\title{
PONTES PARA UMA ATUAÇÃO PSICOFÍSICA: RESENHA CRIATIVA A PARTIR DA PRIMEIRA PARTE DA OBRA PSYCHOPHYSICAL ACTING: AN INTERCULTURAL APPROACH AFTER STANISLAVSKI, DE PHILLIP ZARRILLI.
}

\author{
Edson Fernando \\ Augusto Jones de Aragão
}

\section{Resumo}

Este trabalho se apresenta sob a denominação "resenha criativa". Trata-se de um formato que pretende apresentar ao leitor brasileiro, não versado na língua inglesa, número bastante considerável de passagens textuais em língua portuguesa do primeiro capítulo da obra de Phillip B. Zarrilli intitulada Psychophysical Acting: An intercultural approach after Stanislavski. Para tanto, aproveito a metáfora que Eugênio Barba utiliza para definir esta obra de Zarrilli, isto é, "uma paisagem feita de pontes". A partir desta metáfora desenvolvo uma narrativa na qual dois personagens - Luka Paranoid e Atrizg, mestre e discípula - seguirão atravessando as "pontes" que Zarrilli constrói em sua obra. A travessia, desse modo, se estabelece como a alegoria para a compreensão e prática de uma atuação psicofísica alicerçada no treinamento com artes marciais e meditativas asiáticas. Tal procedimento de escrita encontra-se afinado com a proposta de escrita criativa de Sylvie Fortin.

\section{Palavras-chave:}

Treinamento; Psicofísico; Alegoria.

O nome de Phillip B. Zarrilli ainda é pouco conhecido entre os que se dedicam ao estudo e a prática teatral no Brasil. Seus quase quarentas anos de trabalho dedicados as pesquisas e prática teatral Ihe renderam uma extensa obra que inclui quatro publicações como autor, duas como coautor e outras três como editor. Todas elas abordam, em maior ou menor intensidade, questões pertinentes aos princípios estruturantes para o desenvolvimento de uma atuação psicofísica fundada na prática e cultivo das artes marciais e/ou meditativas asiáticas. Diversos ensaios do autor compõem ainda sua vasta contribuição para o campo das artes cênicas.

\section{Abstract}

This work is presented under the denomination "creative review". It is a format that intends to present to the Brazilian reader, not versed in the English language, quite a considerable number of textual passages in Portuguese language from the first chapter of the work of Phillip B. Zarrilli entitled Psychophysical Acting: An intercultural approach after Stanislavski. To do so, I take advantage of the metaphor that Eugenio Barba uses to define this work of Zarrilli, that is, "a landscape made of bridges". From this metaphor I develop a narrative in which two characters Luka Paranoid and Atrizg, master and disciple will continue to cross the "bridges" Zarrilli builds in his work. The crossing thus establishes itself as the allegory for the understanding and practice of a psychophysical performance grounded in training with Asian meditative and martial arts. Such a writing procedure is in tune with Sylvie Fortin's creative writing proposal.

Keywords:

Training; psychophysical; allegory.

Nenhuma dessas obras recebeu ainda tradução para a língua portuguesa havendo, portanto, uma lacuna para os pesquisadores/artistas brasileiros que se dedicam ao referido tema. Essa é uma das motivações que movem este presente trabalho, um estudo e acompanhamento das principais ideias presentes na primeira parte do último livro, até o momento, publicado por Zarrili: Psychophysical Acting: An intercultural approach after Stanislavski.

Dialogando com vários autores renomados, alguns discípulos diretos de Stanislavski e outros tantos estudiosos da obra do diretor russo, assim como 
com autores da psicologia, filosofia, antropologia, neurociência, teatro, fenomenologia, artes marciais etc., Zarrilli oferece, segundo palavras e o parecer de Eugenio Barba - responsável pela apresentação da obra em inglês - "uma paisagem feita de pontes"P1, pontes que possibilitam a articulação entre três grandes eixos: 1 - Ponte entre a tradição do teatro ocidental e do asiático; 2 - Ponte entre Arte e Ciência; 3 - Ponte entre o trabalho performático e o trabalho do performer na sua vida pessoal. Arquitetando estas pontes Zarrilli, no meu entender, constrói os alicerces que sedimentam sua própria abordagem psicofísica para a atuação a partir da sistematização de um treinamento psicofísico com artes marciais e meditativas asiáticas.

E se você fosse convidado, então, para atravessar estas pontes? Estaria disposto a realizar a caminhada mesmo sem conseguir visualizar o final de cada uma delas? Isto é, estaria disposto a seguir de uma margem à outra sem a certeza das condições estruturais, do tempo de travessia e do que poderá encontrar do outro lado? Este alerta, embora, pareça desanimador se articula às propriedades simbólicas presentes nas narrativas que envolvem "pontes", segundo nos montra Jean Chevalier: "viagem iniciatória (...), local de passagem e de prova (...), poder-se-ia dizer que a ponte simboliza uma transição entre dois estados interiores, entre dois desejos em conflito (...). É preciso atravessá-la; fugir à passagem nada resolveria" (2007, p.729-730).

Então, como não há escapatória é preciso seguir em frente. Os desbravadores personagens que nos permitirão acompanhar sua jornada serão: a ATRIZG, jovem estudante de teatro, filha de agricultores rurais e de uma delicadeza de causar inveja ao porco espinho; e o professor de meia idade $\angle U K A$ PARANOID, adepto da pedagogia "Do C. ao K.", denominação criada por ele próprio para expressar os polos complementares de um aprendizado que concilia a amabilidade e o cuidado - necessários para forjar uma relação de respeito e confiança - com o espírito e prática marcial - necessário para fortalecer os pés descalços dos atravessadores de pontes.

A utilização de personagens para conduzir o leitor ao longo da narrativa não é procedimento inovador. Constantin Stanislavski (1863-1938), o diretor teatral russo que será bastante citado por Zarrilli, já recorreu ao procedimento, nas primeiras décadas do século $\mathrm{XX}$, para oferecer ao leitor um olhar didático e o mais fiel possível dos seus laboratórios de criação teatral. Meu intuito com este procedimento é aproveitar a metáfora das "pontes" sugerida por Barba, expandi-la e trabalhá-la como "alegoria" ao longo de todo o texto, criando um ambiente ficcional-imagético para que os personagens, por meio de sua jornada, nos revelem de modo lúdico os ensinamentos presentes nos textos de Zarrilli. Trabalho com a perspectiva de "alegoria" presente no pensamento do filósofo alemão, Walter Benjamim (18921940), segundo a qual, nas palavras de Joaquim Gama, ela possibilita "a revelação de uma verdade oculta. Em seus estudos, ela não representaria as coisas tais como são, mas uma versão de como foram ou poderiam ser" (2016, p.07). As "pontes alegóricas" que construo a partir dos textos originais de Zarrilli, portanto, pretendem convidar o leitor a desvendar, decifrar, revelar os segredos voltados ao paradigma alternativo para uma atuação psicofísica.

0 uso de personagens interagindo ao longo da narrativa encontra-se articulado ainda ao procedimento metodológico apregoado e defendido por Sylvie Fortin voltado ao desenvolvimento de narrativas que recorrem ao uso imbricado entre teoria e ficção para analisar dados coletados de uma pesquisa. Esta metodologia de escrita vem sendo aplicada em minha pesquisa de doutorado intitulada "ARQUEOLOGITA", sob a orientação da professa Maria Beatriz Braga, pelo programa Dinter UFMG/ UFPA. A partir desta articulação com Fortin e dos elementos citados anteriormente para desenvolvêla, considero este trabalho uma "resenha criativa"; trata-se evidentemente de uma licença poética que me permiti criar aceitando a provocação do professor e pesquisador Luizan Pinheiro que nos instiga a pensar sobre os modos, conteúdos e escritas na pesquisa em arte. Em recente publicação pela Universidade Federal do Pará, ele nos convoca a pensar e investir nas "possibilidades abertas e múltiplas da pesquisa em arte. Princípio ativo do objeto-pesquisa nas mais variadas direções teóricas" (2016, p.24). Seguindo sua perspectiva acredito que

(...) A experiência da Pesquisa em Arte na sua fusão com a Ciência e a Filosofia, atravessa necessariamente essa condição de criação de uma escrita nova. Mesmo que isto implique submeter a língua a uma gagueira, ao seu desequilíbrio perptuo. (idem, p.31). 
Assumo, portanto, o risco de ser considerado um pesquisador gago, não pelo desejo desvairado de subversão dos formatos de escrita acadêmica e sim pelo contexto e natureza de meu objeto- pesquisa.

Antes de passar propriamente a "resenha criativa", destaco ainda quatro elementos importantes quanto à sua estrutura, para apresentar e contextualizar o leitor acerca de alguns elementos técnicos específicos:

1 - o uso de inúmeras citações do texto de Zarrilli diretamente traduzidas do original em inglês. Para tanto, farei uso de uma tradução para fins acadêmicos realizada por Augusto Jones Aragão, graduando de Licenciatura em Teatro/UFPA e membro pesquisador do Grupo de Investigação do Treinamento Psicofísico do Atuante - GITA. Considero que o diferencial desta tradução encontra-se no fato do tradutor (Augusto) e do revisor da tradução (eu), ambos conhecerem e serem iniciados na prática do treinamento psicofísico com artes marciais e meditativas asiáticas sistematizado por Zarrili. Assim, procuramos a partir de nossa prática diária no GITA - eu com uma experiência de aproximadamente dez anos de treinamento psicofísico, e Augusto há mais de um ano praticando - o modo mais adequado de tradução e interpretação desta obra de Zarrili. Desse modo, pretendo oferecer ao leitor brasileiro, não fluente na língua inglesa, um número significativo de passagens com conceitos, ideias, exposições, demonstrações e argumentações presentes na primeira parte do supracitado livro traduzidas para a língua portuguesa. Esta talvez seja a "ponte" inicial que o trabalho estabeleça.

2 - Notas com os textos originais em inglês. Em virtude das inúmeras citações preferimos a utilização das notas, com as respectivas passagens do original em inglês, no final do texto. Phillip Zarrilli ao longo da obra original cita diversos autores, ora em forma de citação direta, ora em forma de citação indireta. Então, sempre que houver uma citação com passagens de texto de autoria do próprio Zarrilli seguidas de citações diretas ou indiretas de outros autores, preservaremos as referencias que já constam no texto original em inglês, evitando assim o excessivo uso do apudpara indicar que as referidas passagens são citadas dentro do próprio texto do Zarrilli. Portanto, apresentaremos sempre ao final da citação original apenas o número da página referente à obra de Zarrilli. As referencias completas da publicação original também poderão ser encontradas na primeira página com as notas originais em inglês.

3 - Formatação do texto: A formatação do texto referente ao recuo de $4 \mathrm{~cm}$ na régua à direita, foi alterado para $2 \mathrm{~cm}$ de cada lado da régua, sugerindo ao leitor a imagem alegórica de pontes entre os textos; e o recuo de $1,5 \mathrm{~cm}$ para início de parágrafo foi eliminado pelos mesmos motivos. As notas de rodapé aparecerão numeradas normalmente. As notas de fim com os originais em inglês, por sua vez, serão sinalizadas com um "P" (de Ponte) seguido do número correspondente da nota.

4 - Opção pelo uso de linguagem coloquial. Para preservar o frescor e a fluidez da narrativa, empregarei o uso da linguagem coloquial sempre que os personagens estiverem dialogando. Os subtítulos seguirão a matriz alegórica já mencionada anteriormente, mas sempre que necessário citarei em negrito o título do tópico traduzido, com o respectivo original em inglês nas notas do fim.

Siga em frente, não se preocupe com o possível balanço das pontes e contemple a paisagem deste horizonte intercultural arquitetado por Phillip Zarrilli.

\section{DE PÉS DESCALÇOS: O SUSTO INICIAL - "CONTEXTO HISTÓRICO"P2:}

Atrizg: Éguaaaaaaaaaaa!!! Onde eu tava com a cabeça quando resolvi parar aqui? Pelo amor de Deus!!! Eu devia tá muito doida do meu cu!!! Vou embora!!! Não vou atravessar isso aí "nem que a vaca tussa"!!!

Luka: Cala a boca e deixa de drama. Já veio até aqui. Não tem volta.

Atrizg: Mas não dá nem pra ver o que tem do outro lado. Não dá pra ver nem se tem outro lado! Olha só: parece uma ponte infinita que não vai levar a lugar nenhum.

Luka: Queres dizer: pontes! Na verdade são pelo menos três que vão se conectando ao longo da trilha.

Atrizg: Tchau mesmo!!! Tô cagando pra essas pontes. Tenho mais o que fazer. Prefiro voltar pra rotina da roça, plantar mandioca, feijão, milho, 


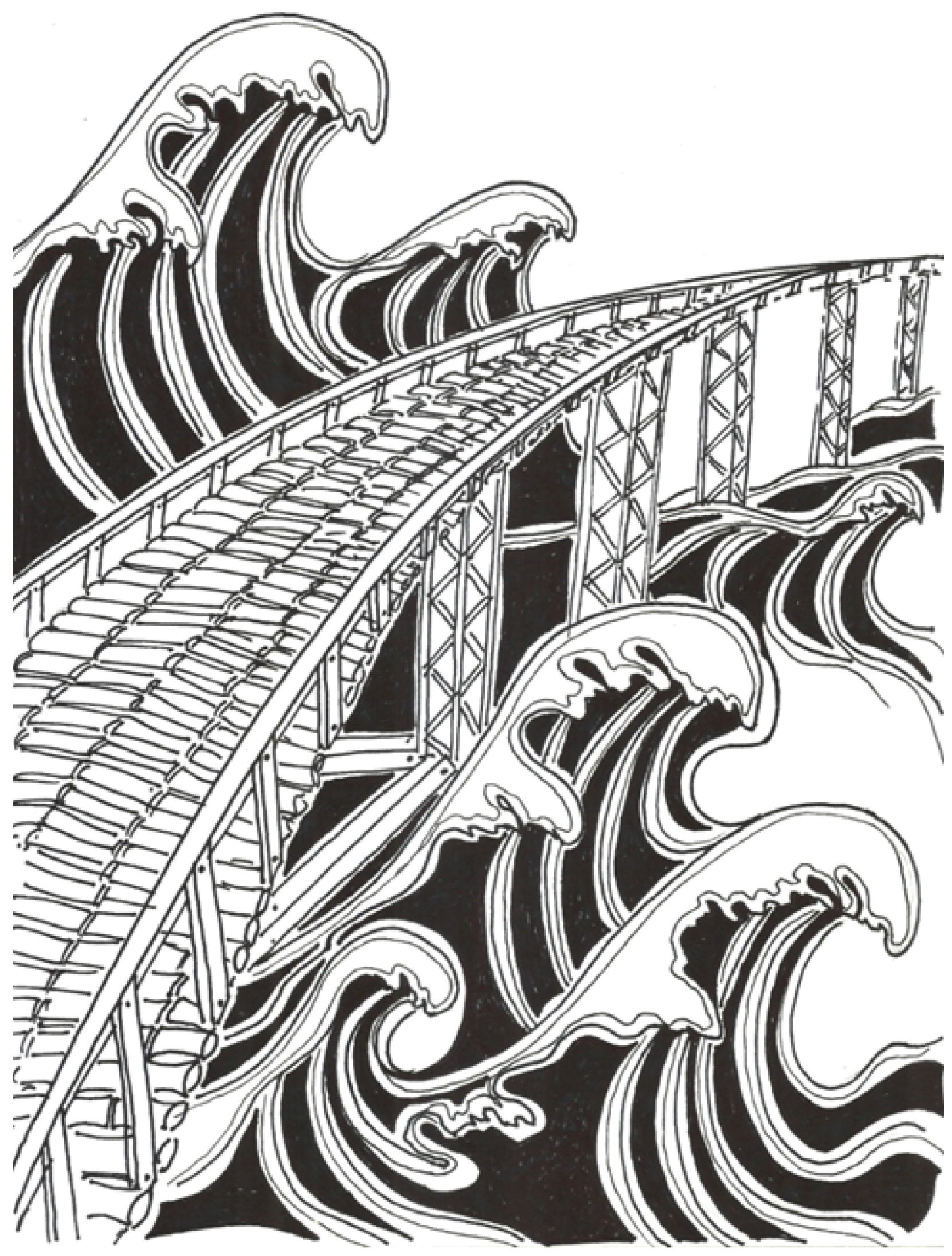

Figura 1 - Ponte sobre o Mar Plato-Cartesianus. Ilustração: Aníbal Pacha 
maxixe, abóbora e quiabo. É duro, o sol castiga, a mão fica igual uma lixa, mas os frutos são certos.

Luka: Pára de frescura e tira logo esses sapatos. Pra seguir a diante devemos ter os pés descalços.

Atrizg: Égua! Daqui a pouco vais pedir pra eu ficar com a "periquita" de fora, também é? Já disse que não vou! Tô fora! Me esquece! Não enche o saco!

Luka: Tá bom então. Vai pro inferno! Mas depois não vem me procurar "pedindo pinico" pelos corredores, pra ajudar nos trabalhinhos teatrais da escola ou da igreja.

(Silêncio longo)

Atrizg: Desculpa. Eu vim até aqui porque quis. Ninguém me obrigou. Ahhhh!!! Mas me assustei. Égua, como é que vou atravessar isso daí descalça e sem saber que rumo tomar?

Luka: E pensas que sou burro de vir aqui de mãos abanando? Claro que não, cabeçuda. Trouxe um mapa e a famosa bússola de Phillip Zarrilli que nos orientará para seguirmos sempre perseguindo o polo norte, terra de habitantes que cultuam a atuação psicofísica.

Atrizg: (tirando os sapatos) Nossa. Isso ajudaria pra caralho se eu soubesse como usar. (atirando uma banda do sapato no mar).

Luka: Calma. Vou começar te mostrando o mapa. Dá só uma olhada. Mas tem paciência, que é um pouquinho grande: Parte I - $O$ que

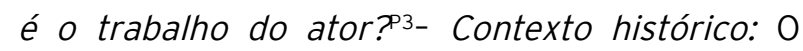
Legado Stanislavski; Versões americanas de Stanislavski; Movendo-se além de Stanislavski; (Re)Considerando o "psicofísico"; A respiração ou energia vital no interior; Metáforas marcando a presença de uma energia animadora. Começando com a respiração: Redescobrindo o corpo e mente através da prática; Treinamento como preparação de atuantes; O ponto inicial: A Respiração / Exercícios preliminares de controle da respiração; Exercício 1; Exercícios 2,3 e 4; 0 exercício do braço não dobrável do aikido; Tensão muscular e intenção; Trabalhando energeticamente com uma imagem ativa; Gráfico 1: Três modos de consciência do corpo-mente; Rumo à atualização de um paradigma psicofísico alternativo de ação através do corpo; Um exemplo de trabalho psicofísico em um ator asiático: dança-drama kathakali; A fisicalização do pensamento: o estado ideal da consciência do ator; Rumo à atualização de um paradigma psicofísico de atuação. Uma abordagem ativa de atuação e expressão: Teorias e metateorias sobre atuação / Improvisação de Beckett em Ohio; Interpretando "leitor" na improvisação Beckett em Ohio / O Problema do corpo e o dualismo corpo-mente; Atuação como um processo de "eu posso": uma visão ativa; A percepção é ativa e relacional; As implicações de uma forma ativa na atuação; Rumo a um modelo dos modos corporificados de experiência do ator; Um paradoxo fundamental: "o corpo ausente"; 0 corpo de superfície extática / Gráfico 2: Os quatro modos de experiência corporais do ator / O corpo visceral "recessivo"; 0 corpo extático interior; 0 corpo exterior extático; O corpo mental do ator como uma gestalt; O corpo do ator como o corpo quiasmático; Discussão final.

Atrizg: Mano, fiquei tonta só de olhar pra essa porcaria aí. Mas fazer o quê? (resignada e jogando o outro lado do sapato no mar) Acho que tô fudida mesmo!

Luka: Vamos lá então. (deixando seu par de tênis na margem da ponte e segurando a mão de Atrizg).

Atrizg: Caramba, isso é pedra!? É pedra bruta! Uma ponte de pedra bruta vai acabar com meu pé. Deixa eu colocar meu sapato?

Luka: (dando os primeiros passos na ponte) Claro que não. E além do mais, acabaste de arremessar o "encardido" no mar. Presta atenção no motivo de começarmos pela ponte de pedras:

O trabalho do ator e diretor de teatro russo,
Constantin Stanislavski (1863-1938), revolucionou
as abordagens ocidentais de atuação no final
do século XIX e início do século XX. Stanislavski
foi o primeiro a usar o termo "psicofísico"
(psikhofizicheskii) voltado à atuação ocidental
para descrever uma abordagem focada tanto na
psicologia quanto na fisicalidade do ator, ambas
aplicadas na atuação do personagem que tem por
base o texto. ${ }^{44}$

Atrizg: Eita porrra! Estas pedras vieram da Rússia? E do início do século passado? Agora que me lasquei de vez. Esta ponte é mais velha que minha avó. Deve tá quase pra cair! E que invenção de moda é esta de "psicofísico"?

Luka: Deixa de ser ignorante e segue caminhando. Não tá vendo a textura e consistência das rochas 
sedimentares que dão sustentação pra ponte? Duvido que houve outro material mais adequado pra enfrentar este mar brabo que tá aí embaixo.

Atrizg: É verdade. Agora que me dei conta que o mar tá bastante agitado.

Luka: Pois é. Ficaste tão assustada com o tamanho da ponte que esqueceste de olhar pro mar que se formou bem embaixo. Isso tem a ver com tua pergunta sobre o "psicofísico". São águas milenares que nasceram da foz do mar chamado Plato-Cartesianus. Reza a lenda que desde Platão quem se banha nestas águas está fadado a acreditar que o corpo é separado da mente. Por isso esta ponte foi construída com rochas sedimentares capazes de resistir à ação do tempo e deste tipo de mar.

\section{Atrizg: E o que isso tem a ver com o psicofísico?}

Luka: Tudo. Afinal estamos caminhando numa ponte que nos levará ao paradigma alternativo de atuação psicofísica. Ou seja, caminhamos com o objetivo de aprender como desenvolver nosso trabalho de atuação sem incorrer numa abordagem que separe o "corpo" da "mente".

Atrizg: Sinceramente, acho tudo papo furado! Pra fazer teatro, basta decorar um texto e incorporar um personagem.

Luka: Acreditamos nisso durante séculos, mas graças a estas pedras russas aqui, hoje podemos pensar e trabalhar de maneira diferente. Olha só como o mapa de Zarrilli nos mostra como estas pedras foram se sedimentando para se tornar esta ponte:

Elementos-chave da abordagem psicofísica
em constante evolução de Stanislavski foram
elaborados a partir de duas fontes principais: o
trabalho do psicólogo Théodule Armand Ribot
(1839-1916) e as versões limitadas do yoga
indiano disponíveis para Stanislavski na Rússia da
virada do século, filtradas através do então popular
ocultismo e espiritualismo (Wegner 1976: 85-89,
Carnicke 1993: 131-145, White, 2006: 73). Desde
seu foco inicial na memória afetiva até seu método
posterior de ações físicas, Stanislavski sempre
tentou superar o que dividia "a mente do corpo, o
conhecimento do sentimento, a análise da ação"
(Benedetti, 1982: 66). ${ }^{\text {P5 }}$

Atrizg: Caramba. Tá ficando complexo. Acho melhor voltar, enquanto ainda consigo ver a margem de onde partimos. Meus pés estão ficando machucados destas pedras.
Luka: Nem pensar. Pega esta pequena trilha de ferro aqui à esquerda, sugerida por Sharon Marie Carnike:

As teorias psicofísicas de [Ribot] [...] afirmam que a mente e o corpo são uma unidade, e que as emoções não podem ser experimentadas sem sensação física [...] Como Stanislavski escreve em O Trabalho do Ator Sobre Si Mesmo, Parte I, "Em cada ação física há algo de psicológico, e no psicológico, algo de físico (Carnicke 1998: 178)". P6

Atrizg: Égua, essa trilha de ferro tá gelada. E esta ponte de ferro range mais que as escápulas velhas da minha rede de dormir.

Luka: Pára de reclamar de tudo e observa como esta trilha de ferro se agrega bem à ponte de pedras de onde partimos.

Stanislavski usa o termo "psicofísico" com seu significado mais evidente e comum: "interrelacionar ou existir entre o físico e o psíquico", ou "participar do físico e do psíquico" (Webster's Third International Dictionary, 1976: 1833). Certamente o trabalho do ator ocorre nesse território entre o que nós ocidentais pensamos como o "físico" e o "psíquico", ou o "exterior" e o "interior". Mas o que constitui cada elemento desse composto? Qual é a relação entre físico e psíquico, exterior e interior? É possível desenvolver uma linguagem e uma teoria da atuação que não sejam vítimas de nosso inerente dualismo ocidental "mente-corpo"? ${ }^{\mathrm{P} 7}$

Atrizg: Tô vendo é a hora de pegar um tétano nesta ponte de ferro, nojenta e enferrujada.

Luka: A salinização do mar é que provoca este desgaste no ferro. Mas não te preocupa. Estamos chegando numa parte onde o ferro está bastante preservado. É só dobrar novamente à esquerda...

Atrizg: (Interrompendo) Agora que percebi esse monte de ramificações que estas pontes vão fazendo. Tá parecendo um labirinto de pontes sobre este mar violento.

Luka: Dobra nesta com a placa indicando Joel Pfister.

Desde meados do século XIX até o século XX, várias versões da psicologia passaram a determinar como os ocidentais costumam pensar e falar sobre o "eu", a experiência e a vida "interior", incluindo as "emoções". Como suposições particulares sobre o "eu" e sobre a subjetividade tornaramse normativos, parecem bastante comuns para ocultar sua invenção histórica. Mas, como explica Pfister em Inventing the Psychological, é crucial "reavaliar a premissa (não histórica)... de que o psicológico é um princípio universal, um 'princípio fixo de inteligibilidade', uma base estabelecida pelos psicólogos - para a explicação da motivação, caráter e comportamento" (Pfister 
e Schnog 1997: 42). Historiadores, sociólogos, psicólogos, atores e teóricos da atuação devem "examinar e contextualizar" o próprio psicológico "como uma categoria histórica, um fenômeno cujos significados culturais e significado social se alteraram ao longo do tempo e, portanto, exigem explicação" (Pfister, 1997: 42). ${ }^{\text {P8 }}$

Atrizg: Quer dizer que este mar violento que é capaz de amaldiçoar quem nele resolver tomar banho, nem sempre foi assim?

Luka: Tá ficando esperta, hein. Isso mesmo. As águas do Plato-Cartesianus ficaram assim turbulentas ao longo da história, e parece que cada vez mais avessas à ideia de integrar "corpo e mente" num organismo só. (Apontando para a próxima curva da trilha de ferro) Hora de voltar para a ponte de pedras.

Atrizg: Oh, xiri!!! Agora que comecei a entender as coisas temos que voltar pra tortura daquela ponte de pedras!

Stanislavski descreveu como a "partitura física" do ator, uma vez aperfeiçoada, deve ir além da "execução mecânica" para um nível "mais profundo" de experiência que "é arredondado com um novo sentimento e... se torna, digamos, psicofísico em qualidade" (1961: 66). Em Minha Vida na Arte, Stanislavski descreveu o ideal estado de consciência ou concentração do ator como aquele em que ele "reage não só em sua visão e audição, mas em todo o resto de seus sentidos. Ele abraça sua mente, sua vontade, suas emoções, seu corpo, sua memória e sua imaginação" (1948: 465). O ideal para Stanislavski era que "em toda ação física... há oculto alguma ação interior, alguns sentimentos" (1961: 228). ${ }^{\text {P9 }}$

Atrizg: A única ação física que desejo realizar agora é sentar e descansar.

Luka: É uma boa ideia, mas anda só mais um pouquinho até aquela estátua indiana cravada no alto do arco da ponte.

\section{Atrizg:(Apontando) Em frente à ponte de bambus?}

Embora o seu conhecimento de yoga fosse limitado e pudesse ter sido extraído exclusivamente de livros em sua biblioteca, Stanislavski adaptou exercícios e princípios específicos de yoga para ajudar a sintonizar e aumentar a percepção sensorial do ator no desempenho. Indiscutivelmente o elemento material mais importante emprestado do yoga por Stanislavski foi o prana (ou o composto sânscrito, prana-vayu) - a respiração, o vento, a energia vital ou a força vital entendida para circular dentro de si. Stanislavski forneceu uma descrição bastante precisa do movimento do prana, como segue:
"O Prana move-se, e é experimentado como o mercúrio, como uma serpente, de suas mãos até as pontas do dedo, de suas coxas aos seus dedos do pé [...] O movimento do prana cria, em minha opinião, ritmo interno" (Carnicke, 1998: 141). ${ }^{\mathrm{P} 10}$

(Sentados diante da estatua indiana e de frente a trilha de bambus)

Luka: Não é linda?

Atrizg: Sinto tranquilidade. Mesmo com o barulho deste mar violento aqui em baixo, olhando pra estátua, consigo relaxar.

Luka: Então, fecha os olhos e tenta fazer este exercício que a Vera Soloviova me contou:

[Nós] trabalhamos muito na concentração. Imaginamos um círculo à nossa volta e enviamos raios de comunicação prana para o espaço e para o outro. Stanislavski diz: "envie o prana para lá eu quero alcançar por meio das pontas dos meus dedos - para Deus - para o céu - ou, mais tarde, para meu parceiro. Eu acredito em minha energia interior e eu a irradio para fora - para expandi-la". (White, 2006: 79) ${ }^{\mathrm{P} 11}$

Atrizg:Caramba!!! Quase dormi, de tanto que relaxei.

Luka: Que bom que conseguiu descansar. Nossa jornada só está no começo. Vamos! (Levantando-se)

Atrizg: (Ainda sentada e relaxada) Vamos seguir pela ponte de bambus?

Luka: Ainda não. Olha só o tanto de trilhas que a ponte de pedras nos oferece (apontando à frente):

O legado de Stanislavski é profundamente diverso. É como um carvalho envelhecido - cada ramo principal com suas próprias torções, voltas, nós etc. - alguns dos quais se transformam em si mesmos. 0 tronco primário e muitos de seus ramos principais incluem aqueles principalmente interessados, como foi o próprio Stanislavski, com atuação de personagens que tem por base o texto. Alguns desses ramos foram desenvolvidos por aqueles que estudaram e/ou trabalharam diretamente com Stanislavski e permaneceram na Rússia, como Maria Osipovna Knebel (1898-1985) ou Vasily Osipovich Toporkov (1889-1970) (Carnicke, 1998: 151). Outros foram desenvolvidos por aqueles que trabalharam e treinaram por um tempo com Stanislavski, mas emigraram da Rússia Soviética para o Ocidente. Os primeiros entre eles estavam Richard Boleslavsky e Maria Ouspenskaya que fundaram o American Laboratory Theater (1923-1926). Michael Chekhov (1891-1955) fundou o Estúdio de Teatro Chekhov em Dartington Hall, Reino Unido (1936/1938), e sobre a emigração para os Estados Unidos desenvolveu sua própria abordagem em Ridgefield, Connecticut (1938/1942) e mais tarde em Hollywood. ${ }^{\text {P12 }}$ 
Atrizg: É muita ponte pra pouca gente! Que inferno. Preferia ficar por aqui, sentada e sentindo o... como é o nome estranho que Stanislavski usa pra fazer os atores respirarem?

Luka: Prana. Espero que não seja só deslumbre de iniciante. Vamos seguir pelas pedras. Anda (Ajudando-na a se levantar).

Atrizg: (Levantando-se e recomeçando a caminhar) Ai minha caceta! Odeio pedras. Ahrrrr! (Pausa) É impressão minha ou esta parte da ponte está com as pedras mais desgastadas?

Luka: Ainda bem que notou. Foi uma parte da ponte bastante atacada e quase caiu.

Sharon Carnicke relata como as autoridades soviéticas estavam tão perturbadas pelo idealismo da filosofia hindu, que informava partes do trabalho de Stanislavski, que "censores atacavam o interesse de Stanislavski pelo yoga" e expurgaram o pranada edição russa de Stanislavski, em 1938, passando a enfatizar o seu método tardio de ações físicas, obscurecendo a importância do simbolismo e do formalismo do yoga em seu trabalho (1998: 144, 1-2).

Nos Estados Unidos, as altamente problemáticas traduções inglesas do trabalho de Stanislavski por Elizabeth Hapgood (Stanislavski, 1936, 1949, 1961), o domínio das versões de métodos americanos da abordagem de Stanislavski e "um ethos orientado individualmente para Freud, privilegiou as técnicas psicológicas do Sistema de Stanislavski sobre as do físico" (Carnicke, 1998: 1). Esta preocupação precoce nos Estados Unidos com a psicologia e a criação de uma vida emocional verdadeira para o personagem significava que, assim como a versão soviética, a importância do simbolismo, formalismo e yoga no sistema de Stanislavski, em constante evolução, também eram obscurecidas. ${ }^{\mathrm{P} 13}$

Atrizg: O que é aquilo brilhando ali distante? (Não contém a ansiedade e sai correndo em direção ao brilho)

Luka: (Gritando) Cuidado! Vai devagar. São pontes... (tentando alcançá-la) Pontes de vidro! (Param no entroncamento entre a ponte de pedras e a ponte de vidro. Ela deslumbrada, ele ofegante e preocupado.)

Quando Stanislavski e o Teatro de Arte de Moscou eventualmente visitaram a América durante os anos de 1923-1924, os atores americanos conheceram uma versão particular de Stanislavski baseada no repertório realista que a companhia realizou e em uma série de palestras públicas sobre o sistema de atuação de Stanislavski. Enquanto nos Estados Unidos, o Teatro de Arte de Moscou apresentou quatro peças de seu bem estabelecido repertório precoce - Tsar Fiodor de Alexei Tolstoi, The Lower
Depths de Maxim Gorki e The Cherry Orchard and Three Sisters de Anton Chekhov (Benedetti, 1999: 282-287), não houve performances do trabalho mais experimental de Stanislavski, como as peças simbolistas de Maeterlinck. / Os atores americanos estavam tão curiosos sobre o "sistema" de Stanislavski que ele deu permissão para que seu ex-aluno e assistente na turnê, Richard Boleslavsky, desse uma série de seis palestras públicas. "Boleslavsky enfatizou a importância da memória emocional, desenvolvendo a técnica para além da prática original de Stanislavski" (Benedetti, 1999: 286). E isso na época em que Stanislavski "colocava maior ênfase em tarefas e ações físicas" no desenvolvimento de seu próprio processo. A combinação de performances do repertório realista e das palestras de Boleslavsky criou uma imagem distorcida e incompleta dos interesses de Stanislavski como diretor, bem como sua abordagem à atuação. ${ }^{\mathrm{P} 14}$

Atrizg: São lindas. Vamos atravessá-las! Por que esta cara de "cu espantado"?

Luka: Não percebeu de onde vem o brilho destas pontes?

Atrizg: Sei lá. O que interessa? O importante é sair deste caminho de pedras. Meu pé tá todo esfolado.

Luka: Estas pontes não possuem brilho próprio, apenas refletem a luz e tudo que está a sua volta. $\mathrm{E}$ esqueceu que estamos atravessando o mar Plato-Cartesianus?

Atrizg: Poxa, mas podemos pelo menos dar uma passadinha por lá?

Luka: Mas vai com calma. Diferente das pedras, estas pontes são frágeis e cortantes.

Provavelmente, o mais influente daqueles que treinaram com Boleslavsky e Ouspenskaya no American Laboratory Theater, mas nunca diretamente com Stanislavski foi Lee Strasberg (1901-1982) - o indivíduo mais identificado com o desenvolvimento da atuação do método americano. (...) Ele se concentrou em desenvolver um ator que "pode criar de si mesmo"... Para fazer isso, o intérprete deve "recorrer ao inconsciente e ao subconsciente" (Krasner, 2000a: 134). Através de exercícios de "memória afetiva", o ator "recorda eventos importantes de sua vida e, em seguida, tenta lembrar apenas as facetas mais intensas" (ibid .: 132). Ao exercitar a "memória afetiva", o ator recorda e experimenta emoções que serão liberadas por ele no palco (ibid .: 133). Strasberg advertiu os atores que a emoção "sempre deve ser apenas emoção lembrada. Uma emoção que acontece agora espontaneamente está fora de controle - você não sabe o que vai acontecer com ela..." (ibid .: 136). Apesar de tais advertências, o fundamento 
do sistema de Stanislavski, como Strasberg ensinou, direcionou-se a encontrar a "verdade emocional" (Smith, 1990: 424-425). ${ }^{\mathrm{P} 15}$

Atrizg: Meu santo caralho! É muita viagem mesmo. Já pensou eu liberando meu "inconsciente"?

Luka: Certamente teríamos uma avalanche de doces obscenidades. (Pausa, risos) Já que enveredamos por aqui vamos seguir até a próxima ponte de vidro à direta, onde consta a trilha de Sonia Moore. E vamos rápido que já entardeceu:

\begin{abstract}
Ao descrever como o ator cria um personagem, Moore dá a impressão de que o personagem é um objeto logicamente construído pela mente (psico) através da análise textual e, em seguida, literalmente colocado dentro do corpo físico em desempenho. Para Moore, a mente é um recipiente - um lugar onde as "emoções" são "armazenadas" (1979: 65) para serem revividas no momento da atuação. Para Moore, a mente afirma o "controle consciente" sobre o corpo e a experiência (ibid.: 34). Ela diz a um de seus alunos, "deixe seu corpo expressar o que você tem em sua mente," (ibid .: 35, ênfase adicionada). Ela convida os alunos a uma imagem na mente e, em seguida, pede: "certifiquese de que seu corpo expressa esta imagem" (ibid .: 37). O que está primeiro na mente é então colocado no corpo. Ela instrui as pessoas a "pensar, pensar e fazer com que seu corpo projete o que está em sua mente" (ibid.: 42, ênfase adicionada). A mente como um recipiente de imagens permanece separada do corpo. O controle é fornecido pelo que Moore várias vezes chama de "pensamento", "lógica" ou "controle consciente", isto é, a mente racional cartesiana. Supõe-se que tudo o que está "na mente" pode ser transferido para o corpo. Precisamente como essa transferência da mente para o corpo ocorre nunca é discutida. ${ }^{\mathrm{P} 16}$
\end{abstract}

Atrizg: Minha santa cacetinha. É impressionante como daqui dá pra perceber bem o reflexo do Plato-Cartesianus na ponte de vidro. Agora entendi tua preocupação.

Luka: Vamos sair daqui antes que escureça de vez. Vamos seguir pela trilha de madeira, logo ali à frente. Ela nos levará de volta até a ponte de pedras.

Das muitas outras abordagens do trabalho baseado em Stanislavski nos Estados Unidos, duas foram criadas quando Stella Adler (19011992) e Sanford Meisner (1905-1997) - ambos membros do Group Theatre e que trabalhavam com Strasberg - romperam com ele em 1934 e 1935 respectivamente. A separação de Adler com Strasberg, em 1934, foi motivada por cinco semanas de trabalho com o próprio Stanislavski em Paris em um papel em Gentlewoman. / "O que mais impressionou Adler foi a insistência de Stanislavski na ação física como base para criar uma poética, sua rejeição de qualquer abordagem direta aos sentimentos e seu abandono, exceto como último recurso, da Memória Emocional que, sob a influência de Boleslavsky, se tornara uma característica da atuação Stanislaviskiana na América. (Benedetti, 1999: 351)" P17

Luka: Segue adiante, vamos passar a noite na ponte de madeira de Bella Merlin.

Ligado à linha de pensamento de Stanislavski, a atriz profissional, autora e professora Bella Merlin sugeriu recentemente que é hora de ir além dele, ou seja, além das limitações das versões anteriores de Stanislavski, indo ao encontro direto com o falecido autor russo, como praticado e ensinado na Rússia. (...) Merlin fornece uma reavaliação articulada, não absurda e pragmática do trabalho psicofísico em Stanislavski à luz dos ensinamentos recentes do autor na Rússia e do estudo da estrutura dramática pós-moderna e do histórico dele (Carnicke, 1998). Focando em particular no processo de Stanislavski da "análise ativa", desenvolvido no final de sua carreira, o ator trabalha constantemente de modo autônomo através da improvisação. A ênfase está em "agir, fazer, experimentar, tocar" (Merlin, 2001: 253). Merlin fornece uma abordagem abrangente e prática de Stanislavski em que não há "divisão entre corpo e mente, mas um contínuo" (ibid .: 27). O estado ideal do ator psicofísico de Merlin é descrito como "constante improvisação interior" (ibid .: 28) - um estado no qual o ator se abre, age e responde ao ambiente performativo em que ele habita no momento. ${ }^{\mathrm{P} 18}$

Atrizg: Não tô vendo onde vou conseguir atar minha rede. Vamos dormir no chão?

Luka: Pensa pelo lado bom: é um chão de madeira, não de vidro. Boa noite.

Atrizg: Ahrrrr. Que inferno!!!

\section{TRABALHANDO COM CORDAS - "COMEÇANDO COM A RESPIRAÇÃO" P19}

Luka: (Sacolejando a Atrizg, que ainda dorme) Acorda. Acorda. Tá na hora de seguir.

Atrizg: (Bocejando) Éguaaaaaaaaaaa!!! O sol ainda nem raiou! Me deixa dormir.

Luka: Deixa de preguiça. Temos muito caminho pra percorrer hoje. (Já seguindo caminho pela ponte de madeira) Tá vendo mais ali na frente, no cruzamento com a ponte de pedras?

Atrizg: (Se espreguiçando e começando a andar contrariada) Mal consigo enxergar meu nariz.

Luka:(Correndo na direção indicada anteriormente; os primeiros raios de sol despontam no horizonte). 
É aqui que começamos. Preparada pro início do treinamento?

Atrizg: (Algum tempo depois ao alcançar Luka, o sol já se mostra completamente no horizonte) Tá falando do quê? (Estarrecida ao se deparar com a nova ponte) Ai meu caralinho!!!

Luka: Tô falando do estado de "quietude no centro"P20, necessário para se "manter imóvel enquanto não se está imóvel" P21. Sem estes princípios, jamais conseguirás atravessar esta ponte de cordas.

Treinar o ator para "se manter imóvel enquanto não se está imóvel" significa necessariamente uma transformação da relação do praticante com seu corpo e mente na prática, e também de como se conceitua a relação entre eles. ${ }^{\text {P22 }}$

Atrizg: (Exclamando) Tô fodida na pica do quati que é de osso e custa a gozar!!! Pára de graça! É impossível seguir por esta ponte. Meus pés tão todos esfolados das pedras; e depois como é que vou me equilibrar numa ponte que é formada somente por duas cordas?

Luka: Tudo bem. Calma. Vamos seguir primeiro por essa ponte de bambus paralela à ponte de cordas. É a ponte que o próprio Zarrilli construiu e atravessou.

Começo com minha própria experiência desse
processo de transformação para ilustrar as
confusões comuns, bem como as peculiaridades
características deste duplo processo. Minha
história ocorre entre as quadras de esporte, em que
muitos homens americanos da minha idade foram
aculturados em práticas e paradigmas particulares
da relação corpo-mente, e Kerala, no sul da
Índia, nos kalaris ou templos físicos e palcos onde
praticantes de Kalarippayattu e a dança-drama
Kathakali são aculturados a uma compreensão e
prática muito diferentes da relação corpo-mente. ${ }^{\text {P23 }}$

Atrizg: (Com certo deslumbre) Esta ponte tem uma estátua parecida com àquela que encontramos antes de fazermos o exercício do prana. Mas ela balança muito.

Luka: Para quem está acostumado a se banhar no Plato-Cartesianus é necessário primeiro sair de suas águas turbulentas, e deixar a pele secar com o tempo. Quietude no centro; persistência; disciplina e muito treino. Este é o segredo. Quanto mais tentarmos enxugar a pele com acessórios inúteis, estaremos provocando mais balanço e instabilidade na ponte de bambus.
Simultaneamente, através do longo processo prático de repetição das formas básicas, gradualmente comecei a sentir uma mudança na qualidade do relacionamento com o meu corpo no exercício ou no palco - estava descobrindo uma energia interna que eu gradualmente podia controlar e modular física e vocalmente no desempenho ou quando, no momento da expiração, sentia a energia ao desferir um golpe. Eu estava passando de uma preocupação com a forma física, externa para a consciência da dimensão (psico) interna mais sutil de como entender completamente uma ação. Meu corpo e minha mente estavam começando a se tornar um, na prática. Eu era capaz de entrar em um estado de maior consciência e sensibilidade para o meu corpo-mente e respiração na ação e, simultaneamente, mantendo minha consciência e energia sensíveis ao ambiente imediato. Eu estava começando a me "manter imóvel, enquanto não se está imóvel". / Enfatizo o início porque todos os dias de prática durante meus períodos iniciais de treinamento na Índia, assistia um mestre como Govindankutty Nayar apresentar este estado ideal de se "manter imóvel, enquanto não se está imóvel". Por exemplo, quando ele executava a postura do leão no kalarippayattu, por trás do êxtase momentâneo havia uma plenitude interior palpável refletida em seu olhar concentrado e em sua prontidão para responder - como um animal - a qualquer coisa que pudesse acontecer no ambiente imediato. Govindankutty Nayar estava apresentando um estado no qual, como o Senhor Brahman, o de Mil Olhos, "o corpo se torna todos os olhos" (meyyukannakuka). Do meu ponto de vista, quando o "corpo se torna todos os olhos", equivale ao mesmo princípio de Benedetti, isto é, se "manter imóvel, enquanto não se está imóvel". Este é o estado ideal de prontidão que o ator deve apresentar. ${ }^{\text {P24 }}$

Atrizg: Tô é paralisada com esta história. Tô achando que é coisa de truque de cinema. Na vida real isso não acontece. Tudo papo furado. Mil olhos? Só tenho três olhos e o terceiro não fica na testa.

Luka: Então, torce pra estar errada, pois do contrário nunca conseguiremos atravessar a ponte de cordas que tá chegando.

Quando A. C. Scott iniciou o "Programa de Teatro Experimental Asiático", em 1963, e encontrou pela primeira vez atores americanos, ele observou: "Fiquei preocupado com o naturalismo casual que os estudantes americanos de teatro associavam a atuação, impressionado pela vitalidade que desperdiçavam desnecessariamente, incomodado pela verborragia articulada na natureza psicológica do teatro e consternado pela sua frágil extensão de concentração que se manifestava em uma atitude pouca disciplinada, que parecia surgir de uma incapacidade de perceber que em um ator silencioso ainda deve permanecer uma presença física no palco e na sala de ensaio". (Scott 1993: 52). ${ }^{\text {P25 }}$ 
Atrizg: (Em frente à outra ponte de cordas) Por que eu fui reclamar das pedras. Bom pelo menos é uma ponte de cordas aparentemente mais instável: tem as duas laterais pra se segurar e tábuas amarradas na base que servem pra firmar os passos. Quer saber: vou passar é correndo pra me livrar disso duma vez só (Sai em disparada atacando a ponte de cordas. Depois dos passos iniciais a ponte começa a balançar a tal ponto que Atrizg, em desespero, se agarra às cordas laterais pra não ser arremessada ao mar).

Luka:(Rindo, se aproximando lenta e tranquilamente) Tanta ansiedade e pressa pra quê? Pra terminar agarrada igual uma lagartixa na parede? Esqueceu do exercício do prana? Da quietude no centro? (Passando por ela e seguindo adiante).

Atrizg: Puta que pariu! Socorro. Me tira daquiiii!!!

Luka: Vou te esperar no entroncamento da próxima ponte de cordas. Vê se não demora. Não esquece da respiração.

\section{Atrizg: Infernooooooooo!!!}

Scott começou a usar o t'ai chi ch' uan para treinar atores "muito antes que o interesse atual nas formas asiáticas de treinamento físico tivesse varrido a América" (Scott, 1993: 52). Implícito no uso de Scott do t'ai chi ch' uan como uma disciplina de treinamento de ator não estava apenas uma rejeição ao tipo de atenção exclusiva dos atores norte-americanos relacionada a um paradigma psicológico e/ou comportamental de atuação, mas também uma tentativa de atualizar um paradigma psicofísico alternativo. ${ }^{\mathrm{P} 26}$

Luka: (Deitado no entroncamento de ponte de cordas). Acho que é ela que está vindo ali. Até que não demorou muito. Foram apenas duas estações do ano. Um bom começo pra quem tem tanta energia explosiva.

Atrizg: Tu és um monstro. Quase morri. Tô toda dolorida, cansada, com o corpo e a mente em frangalhos. Exausta.

Luka: Um bom sinal. Precisamos seguir. A trilha que nos levará até as cordas de Zarrilli não está muito longe. Aproveita os últimos quilômetros pra treinar ainda mais a disciplina. Vais precisar. (Segue novamente sozinho. Com passos mais lentos ela o segue).

Nisto, Scott foi inspirado por Jacques Copeau, por sua própria experiência de praticar t'ai chi $c h^{\prime}$ uan, e pelas suposições religio-filosóficas que informam tais práticas asiáticas tradicionais. Em 1913 Copeau, com Charles Dullin e Louis Jouvet com sua trupe de onze, retiraram-se para o campo francês para treinar e preparar uma companhia e repertório. (...)

Para realizar esse estado de imobilidade, Copeau queria desenvolver uma forma de treinamento do ator que não era o do atleta para quem o corpo permanece um instrumento ou ferramenta. Ele queria um treinamento através do qual "os corpos normalmente desenvolvidos se tornassem capazes de se ajustarem, se entregando a qualquer ação que pudessem fazer". (...)

O que quer que eles façam deve ser feito com simplicidade em um estado de sinceridade, ou seja, "um sentimento de calma e poder... que permita ao artista (...) se apropriar do que está expressando e dirigir sua expressão" (Cole e Chinoy, 1970: 220). P27

Luka: Chegamos.

Atrizg: Não acredito que voltamos pra desgraça desta ponte que só tem duas cordas: uma pra pisar e outra pra se segurar.

Luka: Não voltamos. Avançamos até ela. Não percebes uma pequena diferença?

Atrizg: Vai por inferno!!!

Luka: De nada. Vou te contar mesmo assim. Observa que ela tem pedaços de bambus estabilizando o percurso a cada cinquenta metros de ponte.

Atrizg: Sai da minha frente, senão vou usar estas cordas pra te enforcar. Juro que este é o sonho da minha vida!

Luka: Deixa de drama. Vou seguir na frente. Lembra do que Zarrilli falou: é preciso que o "corpo se torne todos os olhos". (Começa a atravessála. Vez por outra observa de soslaio para ver a reação de Atrizg que se mantém imóvel no início da ponte. Suspirando em voz baixa). Pelo menos já aprendeu a dominar a ansiedade. Vamos, eu sei que consegue.

Baseado em meus anos de treinamento de kalarippayattu com Gurukkal Govindankutty Nayar, C. Mohammed Sherif, Gurukkal de Sreejayan, Mohamedunni Gurukkal, e Raju Asan, no treinamento de t'ai chi ch' uan com AC Scott, e treinamento de hatha yoga com Chandran Gurukkal e Dhayanidhi, eu teci um complementar conjunto de disciplinas psicofísicas que começam e terminam cada dia de treinamento com uma série de exercícios simples de controle da respiração. O treinamento começa com a respiração porque oferece um caminho 
psicofísico para a sintonia prática do corpo e da mente. A respiração atenta fornece um ponto inicial para compreender um estado ideal de consciência corpo-mente e de prontidão em que o "corpo se torna todos os olhos" e é capaz de "se manter imóvel enquanto não está imóvel". P28

Luka: (Entardeceu) Ela continua imóvel. Que merda. (em voz alta) Eu sabia que não ias conseguir. Devias ter ficado na bosta de roça da tua família. Só serves mesmo pra plantar milho e feijão. Me fez perder tempo. Não passa de uma inútil, covarde, fracassada. Devias te jogar de cabeça e se afogar nas águas fétidas do Plato-Cartesianus. Eu me livraria desse fardo imprestável e pestilento que tô carregando há um tempão. Vai pra baixa da égua!!!

Atrizg: (Deixando escapar um leve sorriso no canto da boca e em voz baixa.) O tigre também aprende truques convivendo com o jumento. (Começa a caminhar, muito lentamente provocando instabilidade contínua, mas moderada na ponte, com alguuns momentos de solavancos).

\begin{abstract}
Usando hatha yoga, t'ai chich' uane kalarippayattu, os participantes se permitem explorar três disciplinas corporais, cada uma das quais exige que eles desenvolvam e manifestem sua energia em modos qualitativamente diferentes de corporificação e expressão. No hatha yoga, a pessoa está fisicamente imóvel, mas a sua energia é internamente ativa, animando a postura. Baseado no paradigma da yoga, o kalarippayattu tem momentos de êxtase dentro de sequências que são dinâmicas e fluidas, e manifestam tremendo poder e energia. Embora bonita em seu fluxo, suas sequências têm precisas e fortes liberações imediatas de energia em alguns de seus chutes, saltos e passos. Em contraste, o t'ai chi ch' uan é macio, circular, mas por trás disso a suavidade tem poder e uma força enraizada. ${ }^{\text {P29 }}$
\end{abstract}

Luka: (Num misto de satisfação e indignação) Sua desgraçada filha da mãe. Eu te odeio!

Atrizg: Também te odeio! (Longo silêncio. Ouvemse apenas, o barulho das águas turbulentas do Plato-Cartesianus e de ambas as respirações).

0 processo de treinamento é inicialmente préperformativo. A preocupação inicial não é o fim - em uma apresentação final - mas sim o fato de o ator tomar o tempo necessário para trabalhar em si mesmo. O self em que se trabalha não é o self psicológico/comportamental, mas sim o self psicofísico - o self experiencial/perceptivo constituído no momento pela percepção sensorial, percepção e atenção ao corpo-mente no ato de fazer e como resposta ao ambiente. Ao permanecer dentro dos exercícios, ao não permitir que a mente perca a atenção da respiração sempre presente e ainda manter uma consciência aberta para o ambiente, o praticante começa um processo que explora as sutilezas da relação entre os elementos físico mental/cognitivo/perceptual, tecidos juntos, simultaneamente e em jogo no trabalho incorporado. ${ }^{\mathrm{P} 0}$

(Uma tempestade se forma no céu. Os ventos aumentam consideravelmente provocando forte impacto na ponte que agora balança bastante)

Luka: (olhando sereno pro céu) Vamos seguir. Segura firme nas cordas e mantém a atenção na respiração...

Manter o olho externo focado através de um ponto à frente e manter o olho interior focado em perceber inspirações/expirações para e a partir da região abaixo do umbigo é uma maneira de manter nossas analíticas mentes ocupadas. (...) Idealmente, não se pensa no exercício, mas estando atento à respiração e, literalmente, seguindo-a em sua jornada de ida e volta no corpo-mente, é mais provável que fique imerso no fazer. O praticante entra em uma relação com a respiração através da execução. Depois de várias repetições desses exercícios respiratórios iniciais, convido o praticante a "imaginar que seus olhos literalmente foram transferidos para o abdômen inferior, aproximadamente duas polegadas abaixo do umbigo. 'Olhe' através do ponto de foco externo à frente deste lugar abaixo do umbigo." P31

(A tempestade deságua sobre a ponte que continua balançando bastante)

Atrizg: Tá ficando muito escorregadio. Não tô conseguindo firmar os pés e as mãos. Falta muito pra chegar num lugar seguro?

Luka: Já estais num lugar seguro. Continua trabalhando a respiração, e segue caminhando: um passo de cada vez, sem pensar no passo que veio antes e nem no que vem depois.

Estando com os pés na largura do ombro, os joelhos levemente flexionados, as mãos em seus lados, mantendo o olho externo/olhar focado em frente, mas através do ponto em que seus olhos estão focados. Mantendo os pés firmemente enraizados no chão através das solas dos pés e do olhar externo à frente, permita que o olho interior se concentre na respiração. Mantendo a boca fechada, siga o caminho da respiração na inspiração, seguindo seu caminho através do nariz, e para baixo, para a região cerca de dois a três centímetros abaixo do umbigo. À medida que a respiração chega nesta região, deixe-a encher, expandindo o diafragma. Mantendo o olho interior focado na respiração, siga a expiração de baixo do umbigo para cima através do tronco, através do nariz, mantendo o tempo todo o sentido da conexão da respiração com a região do umbigo à medida que o diafragma se contrai. Repita a inspiração após a respiração 
para baixo, e em uma expiração após a respiração de volta, para cima e para fora. Se houver uma distração, reconheça-a e traga sua atenção e foco de volta para seguir a inspiração ou a expiração. Sentir o momento da iniciação da inspiração, sua continuação à medida que ela é atraída para dentro e para baixo, e o momento de sua conclusão. Sentir o espaço entre este momento de conclusão da inspiração e o momento da iniciação da expiração. Este espaço entre eles é aquele lugar onde reside o potencial de impulso e ação; portanto, é o espaço onde a atuação começa. ${ }^{\mathrm{P} 32}$

\section{(A tempestade se mantém firme)}

Atrizg: Tô tremendo de frio. Não consigo me mexer. $O$ vento frio e os pingos de chuva estão me matando.

Luka: Não tem vento frio; não tem pingos de chuva. Se continuar trabalhando a respiração vai perceber que tu podes te confundir com a tempestade. Não pensa no vento, te tornas o vento; não pensa nos pingos de chuva, te torna os pingos de chuva. Não pensa na tempestade, seja a tempestade.

Mantendo o foco do olho externo no horizonte através do ponto à frente, e mantendo o olho interior na respiração, comece um compromisso ativo com o seguinte: "Imagine que há um lago claro e calmo de água localizado no abdômen inferior, dois dedos abaixo do umbigo - aquele ponto do qual você está olhando. Imagine que esta piscina calma e clara abaixe... através de suas coxas... joelhos... panturrilhas... e direto através dos pés até o chão. Esta constante e clara piscina de água está sempre presente e disponível para você. / Imagine que a partir desta clara piscina calma, há um pequeno fluxo, mas contínuo, de água que começa a subir da piscina... para cima através de seu torso inferior... seu peito... seu ombro direito... Mantenha esse fluxo sempre ligado à piscina abaixo através de seus pés... ela continua a fluir através do ombro direito, braço, cotovelo direito, antebraço e através da palma e as pontas dos dedos da mão direita... Invisível, mas contínuo, o fluxo de água está jorrando agora através das pontas dos dedos até chão... Redirecione esse fluxo lentamente, permitindo que o braço/mão suba à altura do ombro. 0 contínuo do fluxo de água está agora diretamente à frente, saindo pela parede em direção ao ponto de fuga no horizonte em direção ao qual você está olhando. / [0 ajudante é convidado a ficar ao lado do praticante, colocando uma mão logo acima do cotovelo, e a outra sob o pulso.] / Enquanto a ajudante coloca suas mãos, não se distraia. Continue seguindo a respiração. Mantenha a imagem da água que flui constantemente para fora através das pontas dos dedos, calma./ Ajudantes aplicam uma pequena quantidade de pressão... mais... agora o máximo". ${ }^{\mathrm{P} 3}$

(A tempestade continua por meses; a ponte balança. Entre os dois um cúmplice silêncio. Eles avançam sobre a trilha de cordas, demoradamente. Durante a caminhada que segue em silêncio, sobressaltos inesperados de ambos interrompe, por vezes, o estado de tranquilidade cultivado nos semblantes. Segue a tempestade, o vento, a chuva, o balanço da ponte, a silenciosa troca de olhar, de energia, de afeto, de cuidado...)

\section{Atrizg: Sou tempestade...}

Ao praticar exercícios psicofísicos como yoga, kalarippayattue t'ai chi ch' uan, sob a orientação de um professor mestre, assumimos que haverá uma mudança progressiva e refinamento na relação corpo-mente que é diferente da relação corpomente normativa e cotidiana. Como vimos, tal prática começa com o corpo externo e progride do externo para o interno, rumo à realização de uma relação cada vez mais sutil e refinada na prática. ${ }^{\text {P34 }}$

Luka: Se tornou tempestade. Parabéns. Agora se torne ponte. (Avança com passos firmes até o próximo entroncamento de pontes onde há uma pequena plataforma de metal prateada).

Fenomenologicamente falando, nunca se pode experimentar uma mente ou corpo de forma independente... "Aspectos mentais" e "aspectos corporais" foram abstraídos com tanta frequência que há uma tendência a acreditar que esses termos têm correlatos experienciais independentes exatos. Embora possa haver aspectos mentais e aspectos corporais dentro de toda experiência vivida, a presença de qualquer um inclui experiencialmente a presença do outro. Esta relação pode ser descrita como sendo "polar" ao invés de "dual", porque mente e corpo exigem-se uns aos outros como uma condição necessária para ser o que são. A relação é simbiótica. (Shaner, 1985: 42-3) P35

\section{Atrizg: Demorei?}

Luka: O tempo necessário pro teu aprendizado.

Atrizg: A tempestade parou. E agora? O que faremos aqui nesta plataforma?

Luka:Pausa pra aprender a dominar as tempestades que virão. Vamos seguir a trilha de David Edward Shaner. Depois voltamos pras cordas.

Shaner diferencia três modos de consciência do corpo-mente. Em uma das extremidades do espectro está o tipo de consciência "corpo-mente" reflexiva, discursiva (1985: 48), na qual a dimensão sinestésica é menos evidente. Neste modo de consciência, estamos usando o lado direito do nosso cérebro para analisar um problema matemático, resolver um quebracabeça ou fazer a marcação de um texto. Podemos nos tornar completamente absorvidos pensando em algo e, momentaneamente, esquecer que temos um corpo. (...) Nós estamos usando a consciência de terceira 
ordem enquanto escrevemos e/ou lemos. Análise e compreensão de um texto dramático específico é, naturalmente, uma parte importante da preparação para desempenhar um papel específico; contudo, a análise e/ou a pontuação são formas de preparação para abordar a concretização de um papel. ${ }^{\mathrm{P} 6}$

Atrizg: Vejo muita gente completamente absorvida pelas telas dos celulares. O pescoço e a coluna dessas pessoas devem sofrer bastante.

Luka: É um bom exemplo. Só não cai na armadilha de achar que o corpo está segregado da mente, por conta disso. Não está. (Seguem caminhando).

$\mathrm{Na}$ outra extremidade do espectro, a partir de formas proposicionais de conhecimento, é a consciência do corpo- - -mente de primeira ordem que é pré-reflexiva. Imagine que você está fora de casa para uma caminhada na floresta. Você não está determinado a ir a qualquer lugar específico. Não há nada específico em sua mente. Você está simplesmente andando, e em um estado de liberdade, ouvindo o ambiente. Nossa experiência vivida neste estado é a mais ingênua, natural ou inocente. Não há intencionalidade em caminhar, pensar, fazer. Nesse estado "pode-se sugerir que pensamos com nosso corpo e agimos com nossa mente e vice-versa" (1985: 46). ${ }^{\text {P37 }}$

Luka: Tudo é uma questão de onde colocamos a ênfase de nossa consciência. Já percebeu que já faz um tempinho sem nenhum resmungo, palavrão ou rabugice?

\section{Atrizg: Meu xiri!!!}

Luka: Tava demorando.

Atrizg: Tô brincando.

Luka: Então, quando colocamos a ênfase em praguejar a tempestade, investimos energia em tentar compreender por qual motivo tamanha adversidade se abateu sobre nós.

Atrizg: Quando me tornei a tempestade, me integrei a ela sem intencionalidade, sem "porras e caralhos" me enchendo o saco. Caramba. Parece simples, mas sofri pra entender isso.

Luka: Às vezes o problema é que queremos ENTENDER, ao invés de simplesmente agir sem intencionalidades. Mas isso não é tudo. Depois de se tornar tempestade é preciso se tornar ponte.

A consciência do corpo-mente de segunda ordem também é pré--reflexiva, mas com uma diferença. Este é o estado ideal para estar em desempenho através de modos assíduos de prática corporificada, como arte marcial, yoga ou atuação. É um estado não intencional de "presenciar" (Shaner, 1985: 52-53) em que o "horizonte é uma gestalt" de possibilidades. Este horizonte de possibilidades é a estrutura de uma sequência de artes marciais, uma postura de yoga, ou a marcação de atuação desenvolvida em ensaios. No início, um exercício ou ação pode ser preenchido com intencionalidade - estamos tentando fazê-lo ao invés de simplesmente fazê-lo. ${ }^{\text {P38 }}$

Luka: Nunca TENTE fazer alguma coisa. FAÇA. A prerrogativa da TENTATIVA instaura um lapso mínimo de tempo, suficiente para estabelecermos metas idealizadas, projeções que comprometem a qualidade e o fluxo natural do que se passa no momento presente. Não se pode TENTAR ficar pronto para reagir a situações e ambientes. É necessário ESTAR PRONTO.

$\mathrm{Na}$ percepção de segunda ordem, as tensões corporais e as intenções mentais, portanto, recuam para o fundo. "As tensões e as intenções são como a lama colocada em um fluxo claro... Elas se apresentam como obstáculos ao fluxo de presença e a consciência fica enlameada... Quando as tensões e intenções são neutralizadas, a capacidade de resposta à situação pode ser imediata" (ibid.). / Na consciência de corpo-mente de segunda ordem, também se "pensa com o corpo e age com a mente", mas fazemos isso enquanto expressamos a estrutura ou a forma dentro da qual se atua. No desempenho, nossa consciência/ atenção é polar, isto é, move-se inconscientemente entre elementos corporais e perceptivos dentro da atividade estruturada. ${ }^{\mathrm{P} 9}$

Atrizg: É engraçado. Parece papo de filme de arte marcial: "Pensar com o corpo e agir com a mente". Capturar a mosca no ar, dobrar a colher com a mente, arrebentar pedaços de madeira com chutes, saltar de terraços de prédios, mover as coisas de lugar com a força da mente...

Luka: Embora o cinema valorize bastante o lado exótico desse pensamento, quando se treina "mente e corpo" com disciplina, persistência e dedicação somos capazes de coisas surpreendentes. O importante é nunca TENTAR.

Atrizg: Sempre pensei que o segredo fosse exatamente a TENTATIVA.

Luka: Hora de voltar pras cordas. Vamos por aqui (indicando onde fazer a curva).

Os sistemas filosóficos não ocidentais e suas disciplinas relacionadas à prática reconhecem que "a questão do corpo-mente não é simplesmente uma especulação teórica, mas é originalmente uma experiência prática vivida (taiken), envolvendo o 
agrupamento de toda a mente e corpo. O teórico é apenas um reflexo dessa experiência vivida" (Yuasa, 1987: 18). Exceto pelo movimento fenomenológico, a tradição filosófica ocidental sempre perguntou: qual é a relação entre a mente e o corpo? Em contraste, as teorias orientais da mente-corpo começam perguntando: "Como se dá a relação entre a mente e o corpo (através do cultivo)? Ou o que ela se torna? "(Yuasa, 1987: 18). ${ }^{\text {P40 }}$

Atrizg: Já entendi. Mas temos que seguir mesmo pela ponte de cordas do Zarrilli? Passamos uma tempestade de meses nela. Já não foi o suficiente?

Luka: A formação de novas tempestades é quase imprevisível. Por isso devemos estar sempre prontos pra enfrentá-las. Esta ponte de cordas é uma maneira de nos deixar sempre em alerta.

Atrizg: Mas podíamos tirar um dia de folga, umas férias, um descanso, estabelecer um feriado: "o dia da tempestade".

Luka: Cala a boca e vai logo! (Empurrando-a para seguir adiante pelas cordas).

\section{Atrizg: Infernooooo!}

Mas o que, precisamente, é adquirido ou trazido para a realização através de treinamento corporal a longo prazo? O primeiro a ser alcançado é adquirir um certo tipo e qualidade de relação entre quem faz e o que feito. 0 praticante realizador "ideal" é aquele que conseguiu e é capaz de manifestar na prática uma relação intensificada e focalizada (interna e externa) com atos específicos: a concentração para o praticante de meditação, o alvo para o praticante marcial e as tarefas dentro da marcação do ator. ${ }^{\text {P41 }}$

Atrizg: Puta que pariu!

Luka: Tava demorando. O que foi?

Atrizg: Nem parece a mesma ponte de meses atrás.

Luka: A ponte é sempre a mesma. A diferença está em quem faz a travessia.

Atrizg:Hum. Agora tá todo se achando o Sr. Miyagi do norte. Sai pra lá projeto de guru do Jurunas.

Luka: Não te distrai, cabeçuda! Continua.

Ao encontrar um meio de superar a "separação" entre a mente e o corpo, uma compreensão psicofísica e prática de atuação disponibiliza ao ator uma alternativa ao modelo de criação psicológica/ comportamental do personagem, muitas vezes baseado de forma cognitiva. A prática de disciplinas como t'ai chi ch'uan e kalaripayattu permite que os alunos descubram a respiração no corpo e através de exercícios de atuação, aplicar essa percepção qualitativa do corpo ao desempenho. (...) o treinamento em disciplinas psicofísicas intensivas que cultivam o corpo-mente, capacita o ator como um meio de fazer escolhas de atuação encarnadas, e não simplesmente escolhas que permanecem como intenções vazias. ${ }^{\mathrm{P}}{ }^{2}$

Luka: Já que tu estais me sacaneando me chamando de Myiagi do Jurunas, vamos fazer uma pequena incursão pela ponte de bambus do Yuasa Yasuo, "meu primo" de terras muito distantes:

Atrizg: Obaaaa!!! Finalmente pausa pro sushi.

Yuasa afirma que a pessoa sensível ao $k i$, por meio de disciplinas como as artes marciais, ativa "um sistema mediador que liga a mente e o corpo" (ibid.:59), superando assim a dicotomia mentecorpo de Descartes. Para Yuasa, o fluxo interno de $k i$-energia traz à consciência o que ele chama de "circuito emoção-instinto". O indivíduo que apresenta uma consciência intuitiva da energia ki e é capaz de canalizar essa energia em todo o corpo, é capaz de controlar e estendê--la para fora do corpo, seja através de ação vocal, ou em ação física, ou em imagens. ${ }^{\mathrm{P} 3}$

Atrizg: Essa trilha de bambus é um alívio pros pés. "Ki" trilha heim? E "Ki" narrativa maluca é essa hein? (Risos).

Luka: É só ganhar um pouco de confiança que fica toda cheia de gracinhas. Vai brincando com coisa séria. Quero ver na hora "Ki" tiver que usar Ki na tua jornada criativa. Quero ver a cara "Ki" vais fazer quando eu disser "Ki" não tem Ki nenhum na tua atuação, "Ki" tua cena é um grande "KiMerda"!!!

Atrizg: (Séria) Acho melhor nos concentrarmos no "teu primo" de novo. Ahrrrrrrrr!!! (baixo) Que falta de senso de humor.

Quão sem criatividade concebemos a imaginação. Sob a influência do dualismo cartesiano, a imaginação é muitas vezes considerada simplesmente como uma "imagem" concebida como algo na mente. Do ponto de vista de Yuasa e da fenomenologia, imaginar é um ato psicofísico de todo o corpo. Para o ator concretizar uma imagem, como visualizar a gaivota na peça de Chékhov - de mesmo nome - significa muito mais do que ver a gaivota projetada na tela de sua mente. 0 ator treinado através do corpo, que começou a apresentar "ki-sensibilidade", deve ser capaz, de forma intuitiva, de concretizar uma conexão ligada a essa imagem, que é palpável através do corpo do ator - a partir das solas dos pés, através dos olhos e do topo da cabeça. ${ }^{\text {P44 }}$

Luka:É o mínimo que esperamos de alguém que se dedica a jornadas tão duras e extenuantes, como 
as que estamos atravessando. (Súbito) Lembrei de uma coisa importante. Precisamos seguir em direção às novas pontes de ferro.

Atrizg: Que droga, agora que tava curtindo os bambus.

Luka: Rápido. Senão às encontrarmos rápido, corremos o risco de ser confundidos com charlatões.

\section{DO FERRO AO ALGODÃO - "UMA ABORDAGEM ATIVA DE ATUAÇÃO E EXPRESSÃO" P45}

Atrizg: Tem certeza que não podemos continuar pela trilha dos bambus?

Luka: Absoluta. E vê se pára de reclamar. Achei que já tinhas tido experiência suficiente até aqui pra compreender que os caminhos que seguimos são imprevisíveis. Olha ali. (Corre e pára diante de outro entroncamento de pontes) É aqui.

Atrizg: Eita, minha caceta! É imensa, e parece infinita.

Luka: Como todas as outras até aqui.

Atrizg: É, mas esta ponte tem um monte de ramificações, trilhas, bifurcações... A gente vai se perder!

Várias ferramentas metodológicas complementares são usadas para abordar a relação corpo-mente na atuação neste capítulo - a fenomenologia pósMerleau-Ponty de Alva Noë (2004), Drew Leder (1990), Shigenori Nagatomo (1992a, 1992b) e Yuasa Yasuo (1987, 1993); a linguística filosófica de George Lakoff e Mark Johnson (1999, 1980; Johnson, 1987), que reconsideram o papel fundamental da encenação e da experiência em formações linguísticas/ cognitivas; a ciência cognitiva desenvolvida no trabalho de Francisco Varela e colaboradores (1991) e James Austin (1998); e uma abordagem ecológica à percepção desenvolvida pelo antropólogo social Tim Ingold (2000). ${ }^{466}$

Luka: Calma. Esqueceu que trouxemos a bússola do Zarrilli.

Atrizg: Só de olhar fiquei "doidinha do meu cu". E começamos por onde?

Luka: Vamos por essa ponte de ferro que corta as águas do Plato-Cartesianus bem ali onde (apontando)...

Atrizg: (Interrompendo) Mas justo esta que parece desafiar as correntes marítimas. Olha só a força das ondas batendo nas vigas de sustentação. Tá tremendo tudo. Isso não vai dar certo.
Rejeitando a suposição exclusiva das ciências naturais e da psicologia moderna que tratava o corpo físico (Körper) como uma coisa, objeto, instrumento ou máquina sob o comando e controle de uma mente que tudo conhecia, desafiando o pensamento cartesiano, Merleau-Ponty reivindicou a centralidade do corpo (Leib) e determinou a experiência como o próprio meio pelo qual o mundo entra em existência e é experimentado. (...) Para Merleau-Ponty, o foco da investigação filosófica mudou do "eu penso" para um exame do "eu posso" do corpo, ou seja, a sensibilidade como modo de entrar em relação inter-sensorial com objetos ou com o mundo (1964: 87). Dermot Moran resume a contribuição de Merleau-Ponty, sem dúvida nenhuma, como produzindo "o exemplo mais detalhado da maneira pela qual a fenomenologia pode interagir com as ciências e as artes para fornecer um relato descritivo da natureza do ser-no-corpo humano" (2000: 434). ${ }^{\text {P47 }}$

Luka: Não é hora de ficar com medinho bobo. O que seria da história da humanidade sem as grandes obras de engenharia que parecem desafiar as leis naturais?

Atrizg: Olha, eu tô cagando pra leis da natureza. Só quero esta bosta de ponte suporte a fúria das águas desse mar insano e furioso aí embaixo.

Luka: Se chegamos até aqui, podemos seguir com segurança. E vê se te concentras mais na ponte do que no Plato-Cartesianus.

Quando Merleau-Ponty mudou o estudo do "eu penso" para o "eu posso" do corpo, ele colocou o fundamento filosófico para um relato mais processual de como nossa relação com os mundos que habitamos é constituída por nosso envolvimento inter-sensorial e inter-subjetivo com esses mesmos. Entre outros estudiosos, Francisco Varela e seus associados, argumentaram por considerar a experiência e sua relação com o pensamento como processuais - uma visão que desafia o modelo estático idealista. Varela afirma: "Propomos como nome, o termo ativo para enfatizar a crescente convicção de que o pensamento não é a representação de um mundo pré-concebido por uma mente pré-concebida, mas é a determinação de um mundo e de uma mente na base de uma história da variedade das ações que um ser no mundo executa. A abordagem ativa leva a sério, então, a crítica filosófica da ideia de que a mente é um espelho da natureza." (1991: 9) P48

Atrizg: Égua. Agora que percebi que esta é bem diferente daquela ponte de ferro do início de nossa caminhada.

Luka: É sinal de que deslocou a atenção do mar pra ponte.

Atrizg: Aquela ponte do "robô" era de um ferro feio, parecia antigo, desgastado, enferrujado... 
Luka: RIBOT!!! A ponte era do Théodule Armand Ribot. Cabeçuda!!!!

Atrizg: (Rindo) Ah, dá no mesmo. O que importa é que o material é bem diferente.

Luka: É ferro galvanizado. Resiste muito mais aos processos corrosivos.

Implícito na teoria de Merleau-Ponty do corpo como um "eu posso" há uma teoria da percepção. A filosofia ocidental há muito vê a percepção e a ação como distintas. Como Maximilian de Gaynesford explica: "Nesta visão antiga, a mente recebe informações sensoriais de seu ambiente, informações que são então estruturadas por vários processos cognitivos e alimentadas no córtex, motor para produzir ação. Essa visão parece errônea por inúmeras razões neurofisiológicas, comportamentais e filosóficas. Devemos, em vez disso, tratar a percepção e a ação como constitutivamente interdependentes. (2003: 25)" P49

Atrizg: (Falando alto) Tô começando a entender o motivo de usarem este material: o mar parece cada vez mais furioso, por aqui.

Luka: (Também falando alto em virtude do barulho do mar) Vamos pegar aquela trila ali à esquerda.

Atrizg: Não ouvi direito, vai na frente.

Luka: (Tomando a dianteira e indicando) Dobra nessa bifurcação da James Gibson.

Um dos primeiros a desafiar a velha visão da percepção e a defender percepção e a ação como interdependentes foi o psicólogo James Gibson. (...) Gibson adotou uma abordagem radicalmente diferente. Ele rejeitou a noção desenvolvida pela primeira vez por Descartes de que a mente é um órgão separado que opera sobre os dados que os sentidos corporais fornecem. Ele argumentou que: “A percepção [...] não é a realização de uma mente em um corpo, mas do organismo como um todo em seu ambiente, e é equivalente ao próprio movimento exploratório do organismo através do mundo. Se a mente se encontra em algum lugar, então, não é "dentro da cabeça" e nem lá fora no mundo. Pelo contrário, é imanente na rede de caminhos sensoriais que são criados em virtude da imersão do perceptor em seu ambiente. (Ingold, 2000: 3)" P50

Atrizg: (Alto) Por que as pontes têm esses nomes esquisitos?

Luka: (Alto) Pra homenagear quem as construiu.

Atrizg: (Alto) E não tem nenhum João, José, Maria, Ana, Carlos... sei lá. Só esse povo com nome de gente de "nariz em pé".
Luka: (Alto) É nome de gente como a gente. A diferença é que são de terras distantes. (Indicando) Outra bifurcação. Vamos pelo Alva Noë:

Um dos defensores dessa nova visão da interdependência da percepção e da ação é o filósofo Alva Noë. (...) A tese de Noë é que "perceber é uma maneira de agir. A percepção não é algo que acontece a nós, ou em nós. É algo que fazemos... o mundo se torna disponível àquele que percebe através do movimento físico e da interação" (2004: 1). (...) Noë argumenta que a percepção é como a sensação de um toque: "O conteúdo da percepção não é como o conteúdo de um quadro. Ou seja, o mundo dado à consciência não se apresenta de uma só vez, tal como o detalhe pode ser visto num quadro. Na visão, como no tato, nós ganhamos a relação perceptual por pesquisa ativa e exploração. (2004: 33)" P51

Atrizg: (Alto e rindo) O Noë é filho do Noel? Do papai Noel? O Alva, filho daquele de cabelo e barba alva!!!

Luka: (Alto) Tem horas que me dá vontade de te jogar no mar. Deixar tudo pra trás e seguir sozinho.

Atrizg: (Alto) Deixa de drama. Foi só uma piada inocente. Esta jornada já é tão estressante e cansativa, e senão brincarmos um pouco dá vontade de se jogar no mar mesmo.

Luka: (Alto) Certo. Mas não te distrai demais, do contrário podes tropeçar no teu humor e cair lá embaixo do mesmo jeito. (Indicando) Outra bifurcação, Tim Ingold é a ponte agora.

Em paralelo à perspectiva de Noë, o antropólogo Tim Ingold adota uma "abordagem ecológica da percepção" (2000:3) (...). Para Ingold, o "organismo inteiro em seu ambiente" não é um ser limitado, mas sim constituído por um "processo em curso, em tempo real: ou seja, um processo de crescimento ou desenvolvimento" (ibid .: 19-20). Este processo de crescimento ou desenvolvimento consiste na aquisição de habilidades perceptivas. Para Ingold, a noção de habilidades envolve, mas não deve ser reduzida, habilidades corporais; em vez disso, as habilidades perceptivas são "as capacidades de ação e percepção de todo o ser orgânico (mente e corpo indissolúveis) situado em um ambiente ricamente estruturado" (ibid .: 5). ${ }^{\text {P52 }}$

Atrizg: (Alto) Tudo bem. Mas pelo que tô "percebendo", é possível reagir ao ambiente com "humor" e sem distração. Por exemplo: sigo percebendo a textura da ponte, o som furioso do mar se chocando nas vigas de sustentação, a cor do céu, a tua voz, o vento forte... e ainda sim fazer uma piada com o nome da ponte. 
Luka: (Alto) Tens razão. Acho que fiquei ligeiramente mareado. Assume a frente, agora. Pega a bússola.

A experiência perceptiva genuína não depende apenas do tipo e da qualidade da estimulação que recebemos, mas antes é constituída pelo nosso uso ou exercício do conhecimento sensório-motor. "Para que a mera estimulação sensorial constitua a experiência perceptiva - isto é, para que ela tenha um verdadeiro conteúdo que apresente o mundo -, o perceptor deve possuir e usar o conhecimento sensório-motor" (ibid .: 10). O conhecimento perceptivo é, portanto, o conhecimento prático, isto é, o saber nasce por meio das interações com o mundo. ${ }^{\mathrm{P} 3}$

Atrizg:(Alto) Acho que não vamos precisar de bússola. Já consigo enxergar um novo entroncamento de pontes bem à frente. (Corre até lá).

Luka: (Alto) Sem ansiedade, caramba.

Atrizg: Nunca pensei que ficaria feliz em encontrar a ponte de cordas de novo.

Luka:Felizmente, antes de sair voando, a borboleta hiberna em seu casulo.

Atrizg: Até que enfim. Não aguentava mais aquele barulho do mar se chocando com os pilares de ferro.

Luka: O mar continua furioso e barulhento aqui. A diferença é que a ponte está numa altura em que o barulho nos causa menos incômodo.

Atrizg: Já percebi que cada ponte de corda que encontramos é feita de maneira diferente. Esta, por exemplo, parece um triângulo de cabeça pra baixo, feito de três cordas: uma pra andar, e duas pra apoio lateral com as mãos.

Luka: No formato é idêntica à primeira.

Atrizg: Mas tem alguma coisa a mais que não consigo identificar.

Luka: Esta é de fibra de algodão, enquanto àquela era de fibra sintética.

Atrizg: Caramba, é mesmo. Por isso é que dá a sensação de ser leve, suave, macia...

Luka: Preparada pra seguir?

Atrizg:Claro que sim. Este tipo de ponte já conheço há bastante tempo. (Segue em frente).

Desenvolvemos uma bateria ou repertório de habilidades sensório-mo-toras e modos de estar atentos, que são a base do nosso encontro perceptivo com o mundo. No nível mais simples, possuir conhecimento sensório-motor nos permite, por exemplo, compreender nossa relação espacial com as coisas. (...) No nível mais complexo de modos incomuns de prática de habilidades corporais, há uma forma ou sensação cada vez mais sutil que é intrínseca a atividades corporais específicas, como a prática de kalarippayattu, t'ai chi ch' uan ou yoga, ou ao desempenhar um espetáculo bem ensaiado. (...) À medida que se aprende uma forma específica de movimento, como o kalarippayattu, a postura do elefante ou os movimentos de abertura do t'ai chi $c h^{\prime}$ uan na forma reduzida, tanto o padrão quanto a boa qualidade de sua relação com a repetição de cada forma constituem o que Noë descreve como uma forma sensório-motora de conhecimento. ${ }^{\mathrm{P} 54}$

Atrizg: (Bem à frente) Viu só, não tem mais mistério pra mim. Consigo manter o equilíbrio e a tranquilidade sem grandes solavancos. Bem diferente da primeira experiência. Lembra?

Luka:Que bom! (em solilóquio) Espero que continue assim quando a noite chegar: será preciso acender a chama, cultivá-la e seguir caminhando.

Atrizg: Falou alguma coisa?

Luka: (Dissimulando) Pedi pra continuar firme e tranquila.

Quando construímos uma marcação de atuação durante os ensaios, como para Ohio Impromptu, a marcação constitui uma forma de conhecimento corporificado, sensório-motor para o ator. (...) Essas formas de conhecimento perceptivo não estão presentes em lugar algum no meu cérebro, mas sim, o conteúdo dessa experiência perceptual (passada) está virtualmente disponível e presente para mim, o ator. Faço ajustes no momento, conforme necessário. A forma ou a estrutura da marcação de atuação está disponível para a execução no momento em que iniciamos a entrada na encenação/expressão de cada ação na partitura. A estrutura/forma está disponível como um horizonte de possibilidades. ${ }^{\mathrm{P} 5}$

Atrizg: Tá anoitecendo. Vamos parar em algum entroncamento, pra descansar?

Luka: (Firme) Segue.

Atrizg: Mas daqui a pouco não vai dar pra enxergar nada.

Luka: (Firme) Segue!

Atrizg: Que merda!!! Pentelho de buceta escroto!!!

Quando se inicia uma forma de movimento, ou se quando se executa uma marcação de ação, a relação de cada pessoa com cada repetição específica 
da mesma forma ou estrutura é semelhante, mas diferente. Idealmente, no momento presente da ação, não se pensa na forma/estrutura, nem se baseia em alguma representação mental dela, nem se tenta reproduzir a experiência da última repetição; em vez disso, se instaura uma certa relação com a forma/estrutura no momento presente da ação através da consciência perceptiva/sensorial desenvolvida. ${ }^{\mathrm{P} 6}$

Atrizg: Não consigo enxergar mais nada. Égua, não sei o que faço. Tô "doidinha do meu cu".

Luka: Não vais conseguir continuar no escuro, não és Jedi. Então, o que vais fazer?

\section{Atrizg: Te dar um soco na cara!!!}

Luka:Guarda tua energia pra coisa mais importante. Segue em frente, mais adiante encontraremos uma pequena bifurcação iluminada. Já consegues ver?

Atrizg: Ai céus, tô fodida. (Pausa) Ei, tô vendo sim (avança).

\section{Luka: Então, aproveita bem...}

15 de setembro de 2006, o Teatro Gilbert Hemsley, Madison, Wisconsin. Esta noite é a primeira das oito apresentações do Projeto Beckett. Acabamos de receber a nossa chamada de cinco minutos para Ohio Impromptu. Andy Crook (Ouvinte) e eu (Leitor) saímos do nosso camarim, imagens espelhadas um do outro em nossos longos casacos pretos, calças pretas e longas perucas brancas. (...) Entrando no teatro, verificamos a colocação de nossas cadeiras brancas de costas retas, verifiquei com o gerente da casa quanto tempo temos até que eles abrissem as portas e deixassem a plateia entrar. "Três minutos." Tomamos nossos assentos na mesa branca de 4 $X$ 8. Andy e eu nos sentamos em nossas cadeiras. (...) "Dois minutos." Eu verifico a colocação precisa do livro na mesa a minha frente. Seguindo o nosso aquecimento vocal anterior, coloco a palma da minha mão direita no meu esterno e repito um conjunto de pulsos vocais fortes e ressonantes - "ha, ha, ha, há" - num tom que vibra o meu esterno. Com meu foco externo dirigido para fora através do teatro, minha voz "soa" tanto no meu corpo quanto no espaço. (...) Nos últimos momentos antes que a casa seja aberta e o público entre, eu "sôo" o texto vendo se eu acerto o ressonador do peito no passo correto na linha de abertura, (...) Minha atenção muda para minha respiração. Eu sigo minha inspiração enquanto ela lentamente cai desce para o meu abdômen. Mantendo minha atenção primária na minha inspiração e expiração, eu abro a minha consciência auditiva para Andy cerca de três passos à minha esquerda... ouvindo a respiração dele.(...) As portas são abertas e o público, conversando ao entrar, é como uma parede de energia e som que se deslocam para o espaço. Seu som passa por mim. Estou ciente disso, mas não me distraio. Minha consciência sensorial e atenção não são singulares, mas múltiplas, tomando fôlego enquanto tento sincronizar minha respiração com Andy. (...) Seguindo a respiração, quando sinto que o sinal de iluminação está cheio de calor e intensidade, e que a plateia realmente se instalou e a última tosse foi tossida, a primeira linha do texto sai inesperadamente da minha boca. Um tom com pouca cor, mas que, no entanto, ressoa no meu esterno: "Pouco há o que dizer ... Em uma última tentativa .." (...) Assim como minha consciência sensorial/perceptiva está aberta, minha imaginação também está aberta. Ao ler a linha de abertura, as associações momentaneamente se apresentam para mim na periferia da minha consciência/atenção. Normalmente há uma sensação de um fim iminente... o fim desta leitura particular da história - só resta uma página para virar neste livro... o fim de uma vida - a de meu pai... a de minha mãe ...Meu próprio ....? ${ }^{\text {P57 }}$

Atrizg: Não entendi bulhufas. O que estamos fazendo aqui?

Luka: Querias que visses com os próprios olhos. É uma corda de algodão iluminada pela chama de Zarrilli e Andy Crook.

Atrizg: Quem é Andy Crook? Que chama? Do que está falando?

Luka: Falo da chama de vida que todo atuante deve levar consigo, pra iluminar suas pontes de corda de algodão. A chama é pessoal. Cada um deve acender a sua própria chama. E depois de acesa, cuidar pra que ela não apague durante a travessia.

Atrizg: Ai meu xiri! Só faltava essa. Como é que vou fazer fogo aqui no meio do nada?

Luka: Boa pergunta. Mas isso é problema TEU!!! Continua andando...

Andy Crook e eu não somos construções abstratas, mas sim pessoas específicas atuando no momento, isto é, sentindo, percebendo e imaginando um para o outro e para o ambiente, como organismos vivos, humanos. Nessa visão, atuar pode ser definido como esse processo psicofísico através do qual um mundo (teatral) é disponibilizado no momento de sua aparência/experiência tanto para os atores quanto para o público. No entanto, a descrição literal da atuação acima em Ohio Impromptu destina-se a fornecer alguma ideia de quão complexo é o fenômeno encenado e a experiência de atuar no momento em que ela ocorre. ${ }^{\text {P58 }}$

Luka: Agora é contigo. Vai na frente e...

Atrizg: (Interrompendo) Mas ficou tudo escuro de novo. Como é que acendo a desgraça dessa chama???!!! (Acorda balança). 
Luka: Ficar estressada só vai trazer mais problemas. Estavas caminhando no escuro antes. Então, deixa de ataque histérico. Sente as cordas e segue em frente.

À medida que se continua a repetir uma determinada forma ou estrutura ao longo do tempo, um campo maior de experiência se acumula como um campo de possibilidades em expansão. Idealmente, é possível improvisar dentro deste campo maior de possibilidades de movimento/ação. ${ }^{\mathrm{P} 9}$

\section{Atrizg: Odeio ficar no escuro.}

Luka: Nunca vi ninguém conseguir acender um fósforo no meio de uma ventania.

Atrizg: Que vá pro inferno: a escuridão, o fósforo e a ventania.

Luka: CALA A BOCA!!! (Pausa) Sente as cordas.

$\mathrm{O}$ ator envolvido em certas formas de treinamento constrói um repertório de habilidades sensóriomotoras que proporcionam várias possibilidades de ação dentro do ambiente teatral. (...) Contudo, as formas também existem com um segundo conjunto de habilidades sensório-motoras - aquelas para aplicação, isto é, como se pode aplicar a energia/ consciência a várias estruturas de desempenho ou dramaturgias. ${ }^{\mathrm{P} 60}$

Luka: Isso. (Pausa) Em silêncio é bem melhor. Continua...

(...) Então o treinamento que os atores realizam deve fornecer-Ihes um meio prático e empírico de sintonizar suas percepções conscientes para que elas sejam capazes de ser imediatamente ajustáveis e sensíveis ao ambiente de desempenho moldado por uma dramaturgia particular. Este tipo de preparação deve ocorrer em dois níveis: a preparação da percepção consciente do ator, necessária para qualquer ambiente de desempenho e a preparação da consciência perceptual específica para um ambiente de desempenho particular, moldado por cada dramaturgia específica e pela necessidade de cada desempenho específico. ${ }^{\text {P61 }}$

Luka: (Passagem de tempo grande) Leve como algodão. (Pausa) Duro como diamante. (Pausa) Continua...

A marcação de atuação de um ator é uma estrutura que está disponível para ele como uma gama de possibilidades baseadas na lógica estética de uma dramaturgia particular. (...) Trazemos o conhecimento sensório-motor acumulado no treinamento e no ensaio para suportar a experiência real de executar a partitura. No momento da apresentação estamos utilizando nossa experiência perceptiva/sensorial e o conhecimento corporificado cumulativo como exploração habilidosa no momento do mundo teatral específico ou ambiente criado durante o processo de ensaio. ${ }^{\mathrm{P} 62}$

Luka: (Passagem de tempo grande) Uma fagulha apenas... Uma centelha... Nada mais que uma faísca... É o necessário para se começar um incêndio.

De acordo com este paradigma ou metateoria alternativa, pode ser mais útil considerar a atuação em termos de sua dinâmica energética do que em termos de representação. Ao invés de representação, um "teatro energético" - um "teatro não de significado", mas de "forças, intensidades, emoções atuais" (Lyotard, citado em Lehmann, 2006). (...) Nessa visão, o ator praticamente negocia, interior e exteriormente, via percepção em ação, em resposta a um ambiente. ${ }^{\mathrm{P} 63}$

Luka: (Contemplando-a) Lindo. Continua andando. Quando o brilho da chama desperta a noite, convida as sombras pra dançar. Loucos, demônios, sátyros, dragões, gênios, xamãs, ninfas, bruxas, ayamis, quimeras, exus, duendes, grifos, pitonisas, ciclopes, gopis, erês, sacis... Dançam incansavelmente festejando a chegada da viajante. Em rodopios flamejantes ela baila como se fosse a última dança, a última melodia, a última chance de inflamar o próprio ventre fazendo-o arder até o êxtase febril e violento. Incitada pelo alarido eufórico das criaturas da noite, a centelha que Ihe consumia o ventre agora transborda pela genitália, pela boca e pelos olhos, a pele se inflama, o coração distribui lava pelas veias, seu sopro vital irradia labaredas... Dança como se fosse a própria chama sagrada de Huehuetotl... Em rodopios efusivos baila com Agni como se fosse o gêmeo Indra... Transubstanciada pela chama, ela não receia, avança rasgando a escuridão da noite despertando com fúria os prisioneiros da caverna. A eles é preciso cantar, a eles é preciso dançar, a eles é preciso queimar, a eles é preciso anunciar: Enquanto houver chama, haverá encontro! Enquanto houver fogo, haverá celebração!

\section{CITAÇÕES ORIGINAIS}

Referência Bibliográfica do Original:

ZARRILLI, Phillip. Psychophysical Acting: An intercultural approach after Stanislavski. First published 2009 by Routledge 2 Park Square, Milton Park, Abingdon, Oxon ox14 4RN. Simultaneously published in the USA and Canada by Routledge 270 Madison Avenue, New York, NY 10016. 
P1 - Do original: "A landscape made of bridges" (p. 12).

P2 - Do subtítulo original "Historical context" (p. 25).

P3 - Do subtítulo original: "Part I - What is the actor's work?" (p. 24).

P4 - Do original: "Stanislavski was the first to use the term "psychophysical" (psikhofizicheskii) to describe an approach to Western acting focused equally on the actor's psychology and physicality applied to textually based character acting." (p. 25).

P5 - Do original: "Key elements of Stanislavski's constantly evolving psychophysical approach to acting ere drawn from two main sources-the work of psychologist Théodule Armand Ribot (1839-1916) and the limited versions of Indian yoga available to Stanislavski in turn-of-the-century Russia, filtered through the then popular occultism and spiritualism (Wegner, 1976: 85-89; Carnicke, 1993: 131-145; White, 2006: 73). From his early focus on affective memory to his later method of physical actions, Stanislavski always attempted to overcome what divided 'mind from body, knowledge from feeling, analysis from action' (Benedetti, 1982: 66)" (p. 25).

P6 - Do original: " [Ribot's] psychophysical theories [...] state that the mind and body are a unit, and that emotions cannot be experienced without physical sensation [...] As Stanislavski writes in An Actor Works on Himself, Part I, 'In every physical action there is something of the psychological, and in the psychological, something of the physical.' (Carnicke, 1998: 178)" (p. 25).

P7 - Do original: "Stanislavski uses the term 'psychophysical' with its most obvious and commonplace meaning: 'interrelating or existing between the physical and the psychic, 'or 'partaking of both physical and psychical' (Webster's Third International Dictionary, 1976: 1833). Certainly the actor's work takes place in this territory between what we in the West think of as the 'physical' and the 'psychic' or the 'outer' and the 'inner.' But what constitutes each element of this compound? What is the relationship between physical and psychic, outer and inner? Is it possible to develop a language and theory of acting which do not fall prey to our inherent Western body-mind dualism?"' (p. 31).

P8 - Do original: " From the mid-nineteenth through the twentieth century various versions of psychology have come to determine how Westerners usually think and talk about 'the self,' experience, and one's 'inner' life, including the "emotions." As particular assumptions about the 'self' and subjectivity have become normative, they appear sufficiently commonplace to hide their historical invention. But as Pfister explains in Inventing the Psychological, it is crucial 'to reassess the (unhistorical) premise ; that the psychological is a universal, a 'fixed principle of intelligibility,' a basis - established by psychologists - for the explanation of motivation, character, and behavior' (Pfister and Schnog 1997: 42). Historians, sociologists, psychologists, actors, and theorists of acting alike should 'scrutinize and contextualize 'the psychological' itself as a historical category, a phenomenon whose cultural meanings and social significance have altered over time and thus require explanation' (Pfister 1997:42)." (p.31).

P9 - Do original: "Stanislavski described how the actor's 'physical score', once perfected, must go beyond 'mechanical execution' to a 'deeper' level of experience which 'is rounded out with new feeling and; become[s], one might say, psychophysical in quality' (1961: 66). In My Life in Art, Stanislavski described the actor's optimal state of awareness or concentration as one in which he 'reacts not only on his sight and hearing, but on all the rest of his senses. It embraces his mind, his will, his emotions, his body, his memory and his imagination'(1948: 465). Stanislavski's ideal was that 'in every physical action ; there is concealed some inner actionn, some feelings' (1961: 228)." (p. 26).

P10 - Do original: "Although his knowledge of yoga was limited and may have been drawn exclusively from books in his library, Stanislavski adapted specific yoga exercises and principles to help attune and heighten the actor's sensory awareness in performance. Arguably the most important material element Stanislavski borrowed from yoga was prana (or the Sanskrit compound, prana-vayu)-the breath(s), wind, vital energy, or life-force understood to circulate within. Stanislavski provided a fairly accurate description of the movement of prana as it is experienced within as follows: "'Prana moves, and is experienced like mercury, like a snake, from your hands to your fingertips, from your thighs to your toes [...] The movement of prana creates, in my opinion, inner rhythm"'" (Carnicke, 1998: 141)." (p.26).

P11 - Do original: "We worked a great deal on concentration. We imagined a circle around us 
and sent 'prana' rays of communication into the space and to each other. Stanislavski said 'send the prana there - I want to reach through the tip of my finger-to God-the sky-or, later on, my partner. I believe in my inner energy and I give it out-/ spread it.'(White, 2006: 79)." (p. 26).

P12 - Do original: "Stanislavski's legacy is profoundly diverse. It is like an aging oak tree-each major branch with its own unique twists, turns, knots, etc.-some of which turn in on themselves. The primary trunk and many of its major branches include those primarily concerned, as was Stanislavski himself, with textually based character acting. Some of these branches were developed by those who studied and/or worked directly with Stanislavski and remained in Russia, such as Maria Osipovna Knebel (1898-1985) or Vasily Osipovich Toporkov (1889-1970) (Carnicke, 1998: 151). Others were developed by those who worked and trained for a while with Stanislavski, but emigrated from Soviet Russia to the West. First among them were Richard Boleslavsky and Maria Ouspenskaya who founded the American Laboratory Theater (1923-1926). Michael Chekhov (1891-1955) founded the Chekhov Theatre Studio at Dartington Hall, UK (1936-1938) and on emigration to the United States further developed his own approach in Ridgefield, Connecticut (1938-1942) and later in Hollywood." (p. 26-7).

P13- Do original: "Sharon Carnicke reports how Soviet authorities were so troubled by the idealism of Hindu philosophy informing parts of Stanislavski's work that 'censors attacked Stanislavski's interest in yoga,' expunged prana from the 1938 Russian edition of Stanislavski's acting manual, and emphasized his late method of physical actions while obscuring the importance of symbolism, formalism, and yoga in his work (1998: 144; 1-2). I In the United States the highly problematic English translations of Stanislavski's work by Elizabeth Hapgood (Stanislavski 1936, 1949, 1961), the dominance of American method versions of Stanislavski's approach, and 'a Freudian-based, individually oriented ethos [...] privileged the psychological techniques of Stanislavski's System over those of the physical' (Carnicke, 1998: 1). This early preoccupation in the United States with psychology and the creation of a truthful emotional life for the character meant that, like the Soviet version, the importance of symbolism, formalism, and yoga in Stanislavski's ever-evolving system were also obscured." (p. 27).

P14 - Do original: "When Stanislavski and the Moscow Art Theatre eventually toured America during 1923-1924, American actors came to know a particular version of Stanislavski based on the realist repertory the company performed and on a series of public lectures about Stanislavski's acting system. While in the US the Moscow Art Theatre performed four plays from their well-established early repertory-Alexei Tolstoy's TsarFiodor, Maxim Gorky's The Lower Depths, and Anton Chekhov's The Cherry Orchard and Three Sisters (Benedetti, 1999: 282-287). There were no performances of Stanislavski's more experimental work, such as Maeterlinck's symbolist plays. I American actors were so curious about Stanislavski's 'system' that he gave permission for his former student and assistant on the tour, Richard Boleslavsky, to give a series of six public lectures. At precisely the time when Stanislavski was 'placing greater emphasis on physical tasks and physical actions' in the development of his own process, 'Boleslavsky stressed the importance of emotion memory, developing the technique beyond Stanislavski's original practice' (Benedetti, 1999: 286). The combination of performances from the realist repertory and Boleslavsky's lectures created a distorted and incomplete picture of Stanislavski's directorial interests as well as his approach to acting." (p. 28).

P15- Do original: "Arguably the most influential of those who trained with Boleslavsky and Ouspenskaya at the American Laboratory Theater but never directly with Stanislavski was Lee Strasberg (1901-1982) - the individual most identified with the development of American method acting. (...) He focused on developing an actor who 'can create out of himself' ; To do this the performer must 'appeal to the unconscious and the subconscious' (Krasner, 2000a: 134). Through exercises in 'sense memory', the actor 'recalls important events in their life, and then tries to remember only the sensual facets' (ibid.:132). Exercising one's 'affective memory' the actor experiences remembered emotion leading to a release of the actor's emotions on stage (ibid.: 133). Strasberg warned actors that emotion 'always should be only remembered emotion. An emotion that happens right now spontaneously 
is out of control-you don't know what's going to happen from it;' (ibid.: 136). In spite of such warnings the firm foundation of Stanislavski's system as Strasberg taught it lay in finding 'emotional truth' (Smith 1990: 424-425)". (p. 28).

P16 - Do original: "When describing how the actor creates a character Moore gives the impression that the character is an object logically constructed by the mind (psycho) through textual analysis, and then literally put into the physical body in performance. For Moore, the mind is a container-a place where the "emotions" are "stored" (1979: 65) to be re-lived in the act of performance. For Moore, the mind asserts "conscious control" over the body and experience (ibid.:34). She tells one of her students, "let your body express what you have in your mind," (ibid.: 35, emphasis added). She invites the students to take an image in mind, and then "make sure that your body expresses it" (ibid.: 37). What is first in the mind is then put into the body. She instructs people to "think, think and make your body project what is in your mind" (ibid.: 42, emphasis added). The mind as a container of images remains separate from the body. Control is provided by what Moore variously calls "thinking," "logic," or "conscious control," i.e., the Cartesian rational mind. It is assumed that whatever is "in the mind" can be transferred into the body. Precisely how this transfer from mind to body takes place is never discussed." (p.30).

P17 - Do original: "Two of many other approaches to Stanislavski-based work in America were created when Stella Adler (1901-1992) and Sanford Meisner (1905-1997)-both of whom were members of the Group Theater and worked with Strasberg-each broke with him in 1934 and 1935 respectively. Adler's 1934 break with Strasberg was prompted by five weeks of work with Stanislavski himself in Paris on a role in Gentlewoman. I'What struck Adler most was Stanislavski's insistence on physical action as the basis for building a performance, his rejection of any direct approach to feelings and his abandonment, except as a last resort, of Emotion Memory, which, under the influence of Boleslavsky, had become a feature of Stanislavskian acting in America' (Benedetti, 1999: 351)". (p.29-30).

P18 - Do original: "From within the Stanislavski lineage, professional actress, author, and teacher
Bella Merlin has recently suggested that it is time to move beyond Stanislavski, i.e., beyond the limitations of earlier versions of Stanislavski and into a direct encounter with the late Stanislavski as practiced and taught in Russia. (...) Merlin provides an articulate, no-nonsense, and pragmatic reappraisal of Stanislavski's psychophysical process in light of recent teaching of Stanislavski in Russia and scholarship on postmodern dramatic structure and the historical Stanislavski (Carnicke, 1998). / Focusing in particular on Stanislavski's process of "active analysis" developed toward the end of his career, the actor constantly works on her feet through improvisation. The emphasis is "on acting, doing, experiencing, playing" (Merlin, 2001: 253). Merlin provides a comprehensive, practical approach to Stanislavski in which there is 'no divide between body and psychology, but rather a Continuum' (ibid.: 27). The optimal state of Merlin's psychophysical actor is helpfully described as one of 'constant inner improvisation' (ibid.: 28) a state in which the actor opens out to, acts within, and responds to the performative environment she inhabits in the moment." (p. 30-1).

P19 - Do subtítulo original: "Beginning with the breath". (p. 35).

P20 - Do original: "stillness at the center". (p.35).

P21- Do original: "standing still while not standing still" (Zarrilli, 2009, p.35).

P22 - Do original: "Training the actor to "stand still while not standing still" necessarily means a transformation of the practitioner's relationship to his body and mind in practice, and also of how one conceptualizes the relationship between body and mind." (p. 35).

P23 - Do original: "I begin with my own experience of this process of transformation to illustrate the commonplace confusions as well as the idiosyncrasies characteristic of this twofold process. My story takes place between the fields of play on which many American males of my age were enculturated to particular practices and paradigms of the body-mind relationship, and Kerala, South India's kalaris or gymnasia-cum-temples and stages where practitioners of kalarippayattu and kathakali dance-drama are enculturated to a very different understanding and practice of the bodymind relationship." (p. 35). 
P24 - Do original: "Simultaneously, through the long process of repetition of basic forms of practice, 1 gradually began to sense a shift in the quality of my relationship to my bodymind in exercise or on stage - I was discovering an internal energy which I was gradually able to control and modulate physically and vocally whether in performance or when extending my breath or energy through a weapon when delivering a blow. I was moving from a concern with the physical, external form to awareness of the subtler internal (psycho-) dimension of how to fully embody an action. My body and mind were beginning to become one in practice. I was able to enter a state of heightened awareness of and sensitivity to my bodymind and breath in action within, and simultaneously keep my awareness and energy open to the immediate environment. I was beginning to discover how not to stand still, while standing still. / I emphasize beginning because every day of practice during my initial periods of training in India I watched a master such as Govindankutty Nayar actualize this optimal state of 'standing still while not standing still'. For example, when he performed the kalarippayattu lion pose, behind the momentary stasis was a palpable inner fullness reflected in his concentrated gaze and in his readiness to respondanimal-like-to anything that might happen in the immediate environment. Govindankutty Nayar was inhabiting a state in which, like Lord Brahman the thousand-eyed, "the body becomes all eyes" (meyyu kannakuka). From my perspective, when the "body is all eyes" one is "standing still yet not standing still. This is the optimal state of readiness that the actor ideally inhabits." (p. 37).

P25 - Do original: “When A. C. Scott established the Asian Experimental Theater Program in 1963 and first encountered American actors, he observed how:'l was worried by the casual naturalism [American acting students] regarded as acting, impressed by the vitality they needlessly squandered, staggered by their articulate verbosity on the psychological nature of theatre, and dismayed by their fragile concentration span, which manifested itself in a light-hearted attitude toward discipline that seemed to arise from an inability to perceive that a silent actor must still remain a physical presence on both the stage and the rehearsal floor' (Scott, 1993: 52)." (p.38).

P26 - Do original: "Scott began to use taiqiquan to train actors "long before the present interest in Asian physical training forms had swept over America" (Scott, 1993: 52). Implicit in Scott's use of taiqiquan as an actor-training discipline was not only a rejection of American actors' exclusive attention to a psychologically/behaviorally based paradigm of acting, but also an attempt to actualize an alternative psychophysical paradigm." (p. 38).

P27 - Do original: "In this, Scott was inspired by Jacques Copeau, by his own experience of practicing taiqiquan, and by the religiophilosophical assumptions which inform such traditional Asian practices. In 1913 Copeau, with Charles Dullin and Louis Jouvet in his troupe of eleven, retired to the French countryside to train and prepare a company and repertoire. (...) To accomplish this state of motionlessness, Copeau wanted to develop a form of training the actor which was not that of the athlete for whom the body remains an instrument or tool. He wanted a training through which 'normally developed bodies [become] capable of adjusting themselves, giving themselves over to any action they may undertake'. (...) Whatever they do should be done with simplicity in a state of sincerity, that is, 'a feeling of calm and power... that allows the artist... at the same time to be possessed by what he is expressing and to direct its expression' (Cole and Chinoy, 1970: 220)" (p.39).

P28 - Do original: "Drawing on my years of sustained kalarippayattu training with Gurukka Govindankutty Nayar, C. Mohammed Sherif, Sreejayan Gurukkal, Mohamedunni Gurukkal, and Raju Asan, taiqiquan training with A. C. Scott, and hatha yoga training with Chandran Gurukkal and Dhayanidhi, I have woven together a complementary set of psychophysical disciplines that begins and ends each day of training with a series of simple, breath-control exercises. The training begins with the breath because it offers a psychophysical pathway to the practical attunement of the body and mind. Attentive breathing provides a beginning point toward inhabiting an optimal state of bodymind awareness and readiness in which the 'body is all eyes' and one is able to 'stand still while not standing still.". (p. 39).

P29-Do original: "Using hatha yoga, taiqiquan, and kalarippayattu allows participants to explore three corporeal disciplines each of which requires them to garner and manifest their energy in qualitatively 
different modes of embodiment and expression. In hatha yoga, one is physically still, but one's inner energy is internally active, enlivening the pose. Based on the yoga paradigm, kalarippayattu has moments of stasis within sequences that are dynamic and fluid, and manifest tremendous power and energy. While beautiful in its flow, its sequences have sharp, strong, percussive, immediate releases of energy in some of its kicks, jumps, and steps. In contrast, the taiqiquan is soft, circular, yet behind that softness is power and a grounded strength". (p.44).

P30 - Do original: " The process of training is at first pre-performative. The initial concern is not on the end - on performance per se - but rather on having the actor take the necessary time to work on himself. The self on which one works is not the psychological/ behavioral self, but rather the psychophysical self the experiential/perceiving self constituted in the moment by sensory awareness, perception, and attentiveness to one's bodymind in the act of doing and as responsive to the environment. By staying inside the exercises, by not allowing one's mind to wander from attentiveness to the ever-present breath and yet keeping an open awareness to the environment, the practitioner begins a process of exploring the subtleties of the relationship between the physical and mental/cognitive/perceptual elements woven simultaneously together and at play in embodied work." (p. 43-44).

P31 - Do original: "Keeping one's external eye focused through a point ahead, and keeping the inner eye focused on tracking inhalations/ exhalations to and from the region below the navel is a way of keeping our busy, analytical, squirrellike minds occupied. (...) Ideally one does not think about the exercise, but by being attentive to the breath and literally following it on its journey inside the bodymind and back up, one is more likely to stay inside the doing. The practitioner enters into a relationship to the breath through the doing. After several repetitions of these initial breathing exercises, I invite the practitioner to 'Imagine that your eyes have literally been relocated to the lower abdomen, approximately two inches below your navel. 'Look' through the point of external focus ahead from this place below the navel." (p.39).

P32 - Do original: "Stand with the feet at shoulder width, knees unlocked, hands at your sides, keeping the external eye/gaze focused straight ahead, but through the point on which your eyes are focused. Keeping the feet firmly rooted to the ground through the soles of the feet and the external gaze straight ahead, allow the inner eye to focus on the breath. Keeping the mouth closed, follow the path of the breath on the inhalation, tracking its path through the nose, and down, to the region about two to three inches below the navel. As the breath arrives in this region, let it fill out, expanding the diaphragm. Keeping the inner eye focused on the breath, follow the exhalation from below the navel up through the torso, out through the nose, all the time keeping the sense of the breath's connection to the navel region as the diaphragm contracts. Repeat on an inhalation following the breath down, and on an exhalation following the breath back up and out. If there is a distraction, acknowledge it, then bring your attention and focus back to following the in-breath or the outbreath. Sense the moment of initiation of the in-breath, its continuation as it is drawn in and down, and the moment of its completion. Sense the space between this moment of completion of the inbreath, and the moment of initiation of the outbreath. This space between is that place where the potential for impulse and action reside; therefore, it is the space where acting begins." (p.40).

P33 - Do original: "Keeping the external eye focus on the horizon through the point ahead, and keeping the inner eye following the breath, enter an active engagement with the following:Imagine that there is a clear, calm pool of water located in the lower abdomen two inches below the navel-that point from which you are looking. Imagine that this clear calm pool reaches down... through your thighs... knees... calves... and right through the feet and floor to the earth below. This constant, clear pool of water is always present and available to you. Imagine that from this clear calm pool, there is a small but continuous stream of water that begins to rise up from the pool... up through your lower torso... your chest... your right shoulder... Keep that stream always connected to the pool below, and from the pool downward through your feet... it continues to flow through the right shoulder, upper arm, right elbow, forearm, and through the palm and fingertips of the right hand... The invisible but continuously flowing stream of water is gushing out through the 
fingertips now and through the floor... Redirect that flow slowly by allowing the arm/hand to rise to shoulder height. The continuous flow of the stream of water is now directly ahead, out through the wall ahead toward the vanishing point on the horizon toward which you are looking. [The helper is invited to step next to the doer, placing one hand just above the elbow, and the other under the wrist.] As the helper places her hands, do not get distracted. Keep following the breath. Keep the image of water flowing constantly out through the fingertips from the clear, calm pool. Helpers apply a small amount of pressure... more... now maximum."'. (p. 42-43).

P34 - Do original: " When practicing psychophysical exercises like yoga, kalarippayattu, and taiqiquan, under the watchful tutelage of a master teacher, we assume that there will be a progressive alteration and refinement in the body-mind relationship which is different from the normative, everyday body-mind relationship. As we have seen, such practice begins with the external body and progresses from the outside inward toward realization of an ever more subtle and refined relationship in practice." (p. 49).

P35 - Do original: "Phenomenologically speaking, one can never experience an independent mind or body... 'Mindaspects' and 'body-aspects' have been abstracted so frequently that there is a tendency to believe that these terms have exact independent experiential correlates... Although there may be mindaspects and body-aspects within all lived experience, the presence of either one includes experientially the presence of the other. This relationship may be described as being 'polar' rather than 'dual' because mind and body require each other as a necessary condition for being what they are. The relationship is symbiotic. (Shaner 1985: 42-43)." (p. 46-47).

P36 - Do original: "Shaner differentiates between three modes of bodymind awareness (Chart 1). At one end of the spctrum is the type of 'reflexive, discursive consciousness' (1985: 48)-third-order bodymind awareness in which the kinesthetic dimension is least evident. In this mode of consciousness we are using the right side of our brain to analyze a mathematical problem, solve a puzzle, or score an acting script. We can become completely absorbed in thinking about something and momentarily forget we have a body. As I write this sentence I am exercising propositional, analytical knowledge in order to communicate about the complex processes of training, acting, etc. I am obviously not doing acting, but writing about and helping the reader think about the phenomenon of acting as an embodied process. We are both using third-order awareness as we write and/or read. Analysis and understanding of a specific dramatic text is of course an important part of preparing to play a specific role; however, analysis and/or scoring are forms of preparation for approaching the embodiment of a role." (p. 47).

P37 - Do original: "At the other end of the spectrum from propositional forms of knowledge is first-order bodymind awareness, which is pre-reflective. Imagine that you are out for a walk in the woods. You are not intent on going anywhere specific. There is nothing specific on your mind. You are simply walking, and in a state of being open, listening to the environment. Our lived experience in this state is at its most naive, natural, or innocent. There is no intentionality in our walking, thinking, doing. In this state 'one might suggest that we think with our body and act with our mind and vice versa' (1985: 46)." (p. 47).

P38 - Do original: "Second-order bodymind awareness is also pre-reflective, but with a difference. This is hat optimal state of being/doing one accomplishes through assiduous modes of embodied practice such as martial arts, yoga, or acting. It is a non-intentional state of 'presencing' (Shaner, 1985: 52-53) in which the "horizon is a gestalt' of possibilities. This horizon of possibilities is the structure of a martial arts sequence, a yoga pose, or the acting score developed in rehearsals. At first an exercise or action may be filled with intentionality - we are trying to do it rather than simply doing it." (p. 47).

P39 - Do original: "In second-order awareness, both bodily tensions and mental intentions therefore recede into the background. 'Tensions and intentions are like mud put into a clear stream... They dam the flow of presencing and muddy one's awareness... When tensions and intentions are neutralized, one's responsiveness to the situation may be immediate' (ibid.). In second-order bodymind awareness one also "thinks with the body and acts with the mind" but 
one does so while embodying the structure or form within which one acts. In performance, our consciousness/awareness is polar, i.e., it moves un-selfconsciously between bodily and perceptual elements within the structured activity." (p. 47).

P40 - Do original: "Non-Western philosophical systems and their related disciplines of practice have long recognized that 'the mind-body issue is not simply a theoretical speculation but it is originally a practical, lived experience (taiken), involving the mustering of one's whole mind and body. The theoretical is only a reflection of this lived experience' (Yuasa, 1987: 18). Except for the phenomenological movement, the Western philosophical tradition has always asked, what is the relationship between the mind and the body? In contrast, Eastern body-mind theories begin by asking, 'How does the relationship between the mind and body come to be (through cultivation)? Or What does it become?' (Yuasa, 1987: 18)." (p. 49).

P41 - Do original: "But what, precisely, is acquired or brought to accomplishment through long-term bodily based training? First, to be accomplished is to acquire a certain type and quality of relationship between the doer and the done. The accomplished practitioner is one who has achieved and is able to manifest in practice a heightened and focused (internal and external) relationship to specific acts: the object of meditation for the practitioner of meditation, the target for the martial practitioner, and the tasks within the actor's performance score." (p. 49).

P42 - Do original: "In finding a means to overcome the separation between the mind and body, a psychophysiological understanding and practice of acting make available to the actor an alternative to the too often cognitively based model of the psychological/behavioral creation of the character. Practice of disciplines such as taiqiquan, kalarippayattu, and yoga allows actors to discover the breath-in-the body and, through acting exercises, to apply this qualitative bodyawareness to performance." (p. 54).

P43 - Do original: "Yuasa asserts that the kisensitive person, through disciplines such as the martial arts, has activated 'a mediating system that links the mind and the body' (ibid.: 59), thereby overcoming Descartes's mind-body dichotomy. For Yuasa the internal flow of ki-energy brings into awareness what he calls the "emotion-instinct circuit." The individual who actualizes an intuitive awareness of ki-energy and is able to channel this energy throughout the body is able to control and extend it out from the body, whether through vocal or physical action or into active images." (p. 55).

P44 - Do original: "How unimaginatively we have conceived of the imagination. Under the influence of Cartesian dualism, the imagination is too often considered to be simply an image conceived of as something in the mind. From the points of view of Yuasa and phenomenology, imagining is a psychophysiological act of the entire bodymind. For the actor, to actualize an image, such as visualizing the seagull in Chekhov's play by the same name, means much more than seeing the gull projected onto the screen of one's mind. The actor trained through the body, who has begun to actualize ki-sensitivity, should be able intuitively to actualize a full-bodied connection to that image which is palpable through the actor's body-from the soles of the feet through the eyes to the top of the head." (p. 55-56).

P45 - Do original: "An enactive approach to acting and embodiment." Último tópico do capítulo. (p.58).

P46 - Do original: "Several complementary methodological tools are used to address the bodymind relationship in acting in this chapter-the post-Merleau-Ponty phenomenology of Alva Noë (2004), Drew Leder (1990), Shigenori Nagatomo (1992a, 1992b), and Yuasa Yasuo (1987, 1993); the philosophical linguistics of George Lakoff and Mark Johnson (1999, 1980; Johnson 1987) which reconsider the foundational role of embodiment and experience in linguistic/cognitive formations; cognitive science as developed in the work of Francisco Varela and associates (1991) and James Austin (1998); and an ecological approach to perception developed by social anthropologist Tim Ingold (2000)." (p. 63).

P47 - Do original: "Rejecting the exclusive assumption of the natural sciences and modern psychology that treated the physical body (Körper) as a thing, object, instrument, or machine under the command and control of an all-knowing mind, and thereby challenging the Cartesian cogito, MerleauPonty (re)claimed the centrality of the lived body (Leib) and embodied experience as the very means and medium through which the world comes into 
being and is experienced.(...)For Merleau-Ponty, the focus of philosophical inquiry shifted from "I think" to an examination of the "I can" of the body, i.e., sight and movement as modes of entering into intersensory relationships with objects, or the world (1964: 87). Dermot Moran summarizes MerleauPonty's contribution as undoubtedly producing "the most detailed example of the manner in which phenomenology can interact with the sciences and the arts to provide a descriptive account of the nature of human bodily being-in-the-world" (2000: 434)." (p. 63-64).

P48 - Do original: “When Merleau-Ponty shifted from an examination of 'I think' to the 'I can' of the body, he laid the philosophical foundation for a more processual account of how our relationship to the worlds we inhabit is constituted by our inter-sensory and inter-subjective engagement with those worlds. The actor, like other skilled practitioners, ideally gains the ability to inhabit a particular world of the 'I can'. Among other scholars, Francisco Varela and his associates have argued for viewing experience and its relationship to cognition as processual-a view which challenges a static, essentialist, representational model: We propose as a name the term enactive to emphasize the growing conviction that cognition is not the representation of a pregiven world by a pregiven mind but is rather the enactment of a world and a mind on the basis of a history of the variety of actions that a being in the world performs. The enactive approach takes seriously, then, the philosophical critique of the idea that the mind is a mirror of nature. (1991: 9)." (p. 64).

P49 - Do original: "Implicit in Merleau-Ponty's theory of the body as an 'I can' is a theory of perception. Western philosophy has long viewed perception and action as distinct. As Maximilian de Gaynesford explains, On this old view, the mind receives sensory information from its environment, information which is then given structure by various cognitive processes and fed into the motor cortex to produce action. This view seems erroneous for numerous neurophysiological, behavioural and philosophical reasons. We should, instead, treat perception and action as constitutively interdependent.(2003: 2)". (p.64).

P50 - Do original: "One of the first to challenge the old view of perception and to argue for perception and action as interdependent was psychologist James Gibson. (...) Gibson took a radically different approach. He rejected the notion first developed by Descartes that the mind is a separate organ that operates on the data the bodily senses provide. Gibson argued that 'Perception [...] is not the achievement of a mind in a body, but of the organism as a whole in its environment, and is tantamount to the organism's own exploratory movement through the world. If mind is anywhere, then, it is not "inside the head" rather than 'out there' in the world. To the contrary, it is immanent in the network of sensory pathways that are set up by virtue of the perceiver's immersion in his or her environment.' (Ingold 2000: 3)". (p. 65).

P51 - Do original: "One proponent of this new view of the interdependence of perception and action is philosopher Alva Noë.(...) Noë's thesis is that 'perceiving is a way of acting. Perception is not something that happens to us, or in us. It is something we do... the world makes itself available to the perceiver through physical movement and interaction' (2004: 1). (...) Noë argues that perception is like the sense of touch. '[T]he content of perception is not like the content of a picture. In particular, the detailed world is not given to consciousness all at once in the way detail is contained in a picture. In vision, as in touch, we gain perceptual content by active inquiry and exploration.' (2004: 33)." (p. 65).

P52 - Do original: "Paralleling Noë's perspective, anthropologist Tim Ingold takes an 'ecological approach to perception' in which the sentient, perceiving person is considered an organism like other organisms (2000: 3). (...) For Ingold the 'whole-organism-in-itsenvironment' is not a bounded entity, but rather is constituted by an ongoing "process in real time: a process, that is, of growth or development" (ibid.: 19-20). This process of growth or development consists of the acquisition of perceptual skills. For Ingold the notion of skills incorporates, but should not be reduced to, bodily based skills; rather, perceptual skills are the capabilities of action and perception of the whole organic being (indissolubly mind and body) situated in a richly structured environment' (ibid.: 5)." (p. 65-66).

P53 - Do original: "Genuine perceptual experience does not just depend on the type and quality of 
stimulation we receive, but rather is constituted by our use or exercise of sensorimotor knowledge. 'For mere sensory stimulation to constitute perceptual experience - that is, for it to have genuine worldpresenting content - the perceiver must possess and make use of sensorimotor knowledge' (ibid.: 10). Perceptual knowledge is therefore practical knowledge, i.e., one knows how." (p. 66).

P54 - Do original: "We develop a battery or repertoire of sensorimotor skills and ways of being attentive which are the foundation for our perceptual encounter with the world. At the simplest level, possessing sensorimotor knowledge allows us, for example, to grasp our spatial relationship to things. (...) At the more complex level of non-ordinary modes of skillful embodied practice, there is an ever subtler shape or feel that is intrinsic to specific bodily based activities such as the practice of kalarippayattu, taiaiauan, or yoga, or when performing a well-rehearsed performance score. (...)As one learns a specific form of movement, such as kalarippayattu's, elephant pose or the opening moves of shortform taiqiquan, both the pattern and the optimal quality of one's relationship to the repetition of each form constitute what Noë describes as a form of sensorimotor knowledge." (p.66).

P55 - Do original: "When we construct an acting score during rehearsals, as for Ohio Impromptu, the score constitutes a form of embodied, sensorimotor knowledge for the actor. (...) These forms of perceptual knowledge are not present somewhere in my brain, but rather, the content of this (past) perceptual experience is virtually present to me, the actor, as available. I make adjustments in the moment as necessary. The form or structure of the acting score is available for inhabitation at the moment we initiate entry into embodying/expressing each action in the score. The structure/form is available as a horizon of possibilities." (p. 67).

P56 - Do original: "When one initiates a form of movement, or enacting an acting score, one's relationship to each specific repetition of that same form or structure is similar, yet different. Optimally, in the present moment of doing one does not think about the form/structure or draw upon some mental representation of it or try to reproduce the experience of the last repetition; rather, one enters a certain relationship to the form/structure in the present moment of doing through one's cultivated perceptual/sensory awareness." (p. 67).

P57 - Do original: " September 15, 2006, the Gilbert Hemsley Theatre, Madison, Wisconsin. Tonight is the first of eight performances of The Beckett Project. We have just received our five-minute call for Ohio Impromptu. Andy Crook (Listener) and I (Reader) leave our dressing room, mirror images of one another in our long black coats, black trousers, and long white wigs. (...)Entering the theater we doublecheck the placement of our straight-backed white chairs, check with the house manager about how much time we have until they want to open the doors and let the audience enter. 'Three minutes.' We take our seats at the $4^{\prime} \$ 8^{\prime}$ ' white table. Andy and I settle into our chairs. (...) 'Two minutes.' I doublecheck the precise placement of the book on the table before me. Following up on our earlier vocal warm-up, I place the palm of my right hand on my sternum and repeat a set of strong, resonant vocal pulses - 'ha, ha, ha, ha' - in a pitch that vibrates my sternum. With my external focus directed outward through the theater, my voice 'sounds' both my body and the space. (...)In the final few moments before the house is open and the audience enters, I 'sound' the text by seeing if I hit the chest resonator at the correct pitch on the opening line, (...) My attention shifts to my breath. I follow my in-breath as it slowly drops in and down to my lower abdomen. Keeping my primary attention on my in-breath and out-breath, I open my auditory awareness to Andy about three feet to my left. (...) The doors are opened, and the audience, chatting as they enter, are like a wall of energy and sound moving into the space. Their sound passes through me. I am aware of it, but not distracted by it. My sensory awareness and attention are not singular, but multiple - taking in my breathing as it begins to synchronize with Andy's. (...) Following my breath, when I sense the lighting cue is at its full warmth and intensity, and that the audience has indeed fully settled and the last cough has been coughed, the first line of the text unexpectedly comes out of my mouth riding a breath on a pitch with little color but that nevertheless resonates in my sternum: 'Little is left to tell'... In a last attempt... (...) Just as my sensory/perceptual awareness is open, my imagination is also open. As 
I read the opening line, associations momentarily present themselves to me at the periphery of my consciousness/awareness. Usually there is a sense of an impending end... the end of this particular reading of the story-there is only one page left to turn in this book... the end of a life-my father's... my mother's... my own...?" (p. 61-62).

P58 - Do original: "Andy Crook and I are not abstract constructs, but rather specific persons acting, i.e., sensing, perceiving, and imagining as living human organisms in the moment to each other and to the environment. In this view, acting may be denned as that psychophysiological process by means of which a (theatrical) world is made available at the moment of its appearance/ experience for both the actors and audience. However pedestrian, the above description of acting in Ohio Impromptu is intended to provide some idea of just how complex the embodied phenomenon and experience of acting is at the moment it takes place." (p. 62).

P59 - Do original: "As one continues to repeat a particular form or structure over time, a larger field of experience accumulates as an expanding field of possibilities. Ideally one is able to improvise within this larger field of possibilities for movement/action." (p.67).

P60 - Do original: "The actor engaged in certain forms of training builds a repertoire of sensorimotor skills which afford various possibilities of action within the theatrical environment.(...) however, the forms also exist with a second set of affordancesthose for application, i.e., how one might apply one's energy/awareness to various performance structures or dramaturgies." (p. 68).

P61 - Do original: "(...) then the training that actors undertake should provide them with a practical, experiential means of attuning their perceptual awareness so that they are able to be immediately responsive and sensitive to the performance environment shaped by a particular dramaturgy. This type of preparation must take place on two levels - the preparation of the actor's perceptual awareness necessary for any/all performance environments, and the preparation of the actor's perceptual awareness specific to a particular performance environment shaped by each specific dramaturgy and the need of each specific performance score." (p.68).
P62 - Do original: "An actor's performance score is a structure that is available to the actor as a certain range of possibilities based on the aesthetic logic of a particular dramaturgy. (...) We bring the sensorimotor knowledge accumulated in training and rehearsal to bear on the actual experience of enacting the score. In the moment of enactment we are utilizing our perceptual/ sensory experience and cumulative embodied knowledge as skillful exploration in the moment of the specific theatrical world or environment created during the rehearsal process." (p. 68).

P63 - Do original: "According to this alternative paradigm or meta-theory, it may be more useful to consider acting in terms of its dynamic energetics than in terms of representation. Rather, it implies an "'energetic theater"'-a 'theater not of meaning but of 'forces, intensities, present affects' (Lyotard, quoted in Lehmann 2006: 37) (...) In this view the actor practically negotiates interior and exterior via perception-in-action in response to an environment." (p. 69).

\section{REFERÊNCIAS}

BENJAMIN, Walter. Magia e Técnica, Arte e Política: Ensaios sobre literatura e história da cultura. Trad. Sergio Paulo Rouanet. São Paulo: Brasiliense, 1994.

\section{Origem do drama trágico}

alemão. Trad. João Barrento. Belo Horizonte: Autêntica Editora, 2011.

Rua de mão única: infância berlinense. Trad. João Barrento. Belo Horizonte: Autêntica Editora, 2013.

CHEVALIER, Jean. GHEERBRANT, Alain. Dicionário

de símbolos: (mitos, sonhos, costumes, gestos, formas, figuras, cores, números). Com a colaboração de André Barbaault. Trad. Vera da Costa e Silva. $21^{a}$ Ed. Rio de Janeiro: José Olympio, 2007.

FORTIN, Sylvie. Contribuições possíveis da etnografia e da autoetnografia para a pesquisa na prática artística. In: Revista Cena. Porto Alegre: Programa de Pós Graduação em Artes Cênicas Instituto de Artes da UFRGS, n. 7, 2009.

\section{Considerações metodológicas} para a pesquisa em arte no meio acadêmico. In 
Revista de Pesquisa em Arte ABRACE, ANPAP e ANPPOM em parceria com a UFRN. Vol. 01, $\mathrm{n}^{\circ}$ 01, Jan-Jun, 2014.

GAMA, Joaquim C. M. Alegoria em jogo: $A$ encenação como prática pedagógica. São Paulo: Perspectiva, 2016.

PINHEIRO, Luizan. Anarcometodologia: 0 que pode uma pesquisa em arte. Belém: UFPA, 2016.

\section{SOBRE OS AUTORES}

Edson Fernando Santos da Silva é Bacharel e Licenciado Pleno em Filosofia pela Universidade Federal do Pará - UFPA (2001); Especialista em Semiótica e Artes Visuais pelo Instituto de Ciências da Arte ICA - UFPA (2005); Mestre em Artes pelo Programa de Pós-Graduação em Artes do Instituto de Ciências da Arte ICA - UFPA (2009/2010). Doutorando do Programa DINTER UFPA / UFMG. Curso Técnico de Formação de Ator da Escola de Teatro e Dança da UFPa (1999/2000). Professor do Magistério Superior da UFPA - ETDUFPA. Experiência na área de Filosofia, com ênfase em Estética, atuando principalmente nos seguintes temas: teatro, celebração, tragédia, cultura e apresentações. Atuante na cena teatral paraense desde 1996 como ator e diretor.

Augusto Jones de Aragão Barbosa Junior é graduando em Licenciatura Plena em Teatro. Tem experiência na área de Artes, com ênfase em Teatro. 